


\title{
ABSENTEÍSMO - DOENÇA: LEVANTAMENTO DE ESTUDOS SOBRE PERFIL DE ADOECIMENTO EM UM PROGRAMA DE MESTRADO PROFISSIONAL - PROFEPT
}

\footnotetext{
${ }^{1}$ Natália Ferraz Pavanelli Ormond, ${ }^{1}$ Rosicleia Moreira Santos, ${ }^{2}$ Ed' Wilson Tavares Ferreira, ${ }^{2}$ Geison Jader Mello, ${ }^{2}$ Vanderley Severino dos Santos

${ }^{1}$ Discentes do Mestrado Profissional em Educação Profissional e Tecnológica (ProfEPT), IFMT.

2 Docentes do Mestrado Profissional em Educação Profissional e Tecnológica (ProfEPT), IFMT.

E-mail: natypavanelli@gmail.com
}

\author{
Recebido em: 15/11/2021 - Aprovado em: 15/12/2021 - Publicado em: 30/12/2021 \\ DOI: 10.18677/EnciBio_2021D2 \\ trabalho licenciado sob licença Creative Commons Attribution-NonCommercial-NoDerivatives 4.0 International License.
}

\section{RESUMO}

Considerando a necessidade de obtenção de indicadores sobre os afastamentos do trabalho por motivos de saúde pelos servidores públicos federais de ensino tecnológico, este estudo tem o objetivo de analisar como esse tema vem sendo estudado no Programa de Mestrado em Educação Profissional e Tecnológica (ProfEPT), ofertado pela Rede Federal de Educação Profissional e Tecnológica. Bem como, analisar os dados de afastamentos por motivo de saúde do servidor do Subsistema Integrado de Atenção à Saúde do Trabalhador (SIASS) de 2019, obtidos junto ao Instituto Federal de Mato Grosso (IFMT). Dessa forma, para a elaboração desta pesquisa quali-quantitativa, de análise bibliográfica e de caráter exploratório, foram utilizadas as palavras "absenteísmo" e "saúde", nas buscas realizadas por trabalhos concluídos, na plataforma digital "Observatório ProfEPT", entre 2019 a 2021. Entre os resultados, verificou-se que é cada vez mais necessário investigar se os agravos à saúde dos servidores estão relacionados às suas atividades e ao ambiente de trabalho. Também foi verificado que os servidores são mais acometidos por doenças do grupo F00-F99 - transtornos mentais e comportamentais. Os maiores números de afastamentos são de servidores técnicos, porém os docentes se afastam por mais tempo.

PALAVRAS-CHAVE: Absenteísmo; IFMT; ProfEPT; Saúde Servidor.

\section{ABSENTEEISM-DISEASE: SURVEY OF STUDIES ON ILLNESS PROFILE IN A PROGRAM IN PROFESSIONAL AND TECHNOLOGICAL EDUCATION - PROFEPT}

\section{ABSTRACT}

Considering the need to obtain indicators about the absences from work for health reasons by federal public servants of technological education, this study aims to analyze how this topic has been studied in the Master's Program in Professional and Technological Education (ProfEPT), offered by the Brazil's Federal Network of 
Professional and Technological Education. As well as, analyze the data of absences due to health reasons from the servants, in the Integrated Subsystem for Workers' Health Care (SIASS) from 2019, obtained from the Federal Institute of Mato Grosso (IFMT). Thus, for the preparation of this quali-quantitative research, of literature analysis and exploratory nature, the words "absenteeism" and "health" were used in the searches conducted by completed works, in the digital platform "ProfEPT Observatory", between 2019 and 2021. Among the results, it was found that it is increasingly necessary to investigate whether the health problems of servants are related to their activities and work environment. It was also verified that the public servants are more affected by diseases of the F00-F99 group - mental and behavioral disorders. The largest numbers of absences are from technical servants, but teachers move away for longer period.

KEYWORDS: Absenteeism; IFMT; ProfEPT; Health Servant.

\section{INTRODUÇÃO}

O trabalho é parte inerente da história humana, indispensável para 0 desenvolvimento individual e coletivo, além de ser um dos principais meios para a aquisição de identidade, reconhecimento, realização pessoal e uma das fontes de satisfação das necessidades humanas (MURCHO; JESUS, 2014). Ainda, conforme Saviani (2007), o trabalho é inerente ao homem, trabalho e educação são atividades especificamente humanas. Isso significa que, rigorosamente falando, apenas o ser humano trabalha e educa. Entretanto, o trabalho pode tanto ser fonte de prazer quanto de mal-estar para o trabalhador, visto que requer um custo humano intrínseco (SANTOS, 2014).

Nesse contexto, a maneira como as pessoas interpretam o mundo ao seu redor pode ser fator que incide sobre o adoecimento (MENDES, 2015). Assim, esse custo humano pode ser eficaz e promover o bem estar, a saúde e, a qualidade de vida no trabalho (QVT); ou ineficaz, ocasionando mal-estar, risco de adoecimento e acidentes. Dessa maneira, a promoção da saúde e prevenção de doenças ocupacionais, tornam-se medidas de suma importância para a manutenção da saúde dos trabalhadores.

Os estudos nessa área destacam que apesar das melhorias nas condições de trabalho nos últimos 100 anos, as taxas de afastamento do trabalho por doenças seguem aumentando, especialmente em países industrializados (CUNHA et al. 2009). No Brasil, Santi et al. (2017), mostraram essa mesma tendência no serviço público entre os anos de 1995 e 2005, especialmente entre mulheres e trabalhadores acima de 40 anos (BRASIL, 2017). Embora as causas de afastamento sejam diversas e nem sempre estejam relacionadas diretamente ao trabalho - os servidores podem se afastar por variadas questões como: afastamento para capacitação, acompanhamento de cônjuge, licença maternidade entre outros; as taxas de absenteísmo podem ser vistas como importante indicador da avaliação da saúde dos trabalhadores e das condições nas quais o trabalho é realizado, além das políticas institucionais de recursos humanos (MURCHO; JESUS, 2014).

Ainda com uma definição relativamente simples, o absenteísmo é um fenômeno complexo e multifatorial que envolve fatores psicossociais, econômicos, culturais e relacionados ao ambiente de trabalho (PENNATI et al. 2006) que resulta em prejuízos tanto para o trabalhador quanto para o empregador e a instituição.

Nessa perspectiva, o objetivo deste trabalho é analisar de que forma os estudos com foco no absenteísmo-doença e saúde dos servidores públicos federais, tem sido abordado no Programa de Mestrado em Educação Profissional e 
Tecnológica (ProfEPT) da Rede Federal de Educação Profissional e Tecnológica em face à existência da linha de pesquisa Organização e Memórias de Espaços Pedagógicos na Educação Profissional e Tecnológica (EPT). Bem como, analisar os dados de afastamentos por motivo de problemas com a saúde catalogados pelo SIASS no ano de 2019.

Desse modo, para Cunha et al. (2009) pesquisas que se ocupam em abordar a temática da saúde dos servidores públicos e, as principais causas de acometimentos de afastamento, tornam-se imprescindíveis para subsidiar debates sobre a condição de saúde e doença dos trabalhadores, contribuindo para construção de indicadores que possam fomentar e fortalecer as ações de promoção, prevenção e reabilitação da saúde estabelecida na PASS.

\section{REVISÃO BIBLIOGRÁFICA}

A Educação Profissional e Tecnológica - EPT compreende os processos educativos em espaços formais e não formais relacionados ao mundo do trabalho e à produção de conhecimento, numa perspectiva interdisciplinar, com vistas à integração dos campos do Trabalho, da Ciência, da Cultura e da Tecnologia (IFES, 2021). O programa de mestrado ProfEPT, possui duas linhas de pesquisas que abrigam diversas possibilidades de projetos, são elas: Práticas Educativas em EPT e Organização e Memórias de Espaços Pedagógicos na EPT.

Sendo assim, a linha "Práticas Educativas em EPT", trata dos fundamentos das práticas educativas e do desenvolvimento curricular na EPT em suas diversas formas de oferta, com foco nas estratégias transversais e interdisciplinares, que possibilitem formação integral e significativa do estudante, sustentados no trabalho como princípio educativo e na pesquisa como princípio pedagógico, em espaços formais e não formais. Os macro-projetos dessa linha são: Propostas metodológicas e recursos didáticos em espaços formais e não formais de ensino na EPT, Inclusão e diversidade em espaços formais e não formais de ensino na EPT e Práticas Educativas no Currículo Integrado.

Já a linha de pesquisa Organização e Memórias de Espaços Pedagógicos na EPT, trata dos processos de concepção e organização do espaço pedagógico na EPT, com foco nas estratégias transversais e interdisciplinares, que possibilitem formação integral e significativa do estudante, sustentados no trabalho como princípio educativo e na pesquisa como princípio pedagógico, em espaços formais e não formais. Nesta linha de pesquisa os macro-projetos são: História e memórias no contexto da EPT, Organização do currículo integrado na EPT, Organização de espaços pedagógicos na EPT. Neste último macro-projeto, podem ser abrigados estudos que se ocupam de questões relacionadas à organização e planejamento de espaços pedagógicos, formais e não formais, da pesquisa, do ensino, da extensão e eles devem investigar as relações desses espaços com a EPT e as suas interlocuções com o mundo do trabalho e os movimentos sociais (IFES, 2021).

Dentre as questões que podem ser investigadas para a melhoria da Gestão da EPT, está a questão da saúde do servidor, uma vez que a diminuição das ausências ao trabalho por motivos de doença refletirá nos serviços ofertados pela instituição.

Assim sendo, a ausência do servidor ao trabalho, denominada absenteísmo (ou, também, ausentismo e absentismo), é um indicador que representa as faltas em relação ao número de dias úteis previstos de trabalho. Esse termo passou a ser utilizado com o advento da Revolução Industrial e, a partir de então, foram indicados os principais tipos de absenteísmo, de acordo com sua motivação: 
- voluntário: por razões particulares não justificadas por doença;

- por doença: incluídas todas as doenças, exceto as decorrentes do trabalho;

- por patologia profissional: com relação a acidentes de trabalho ou doenças profissionais;

- legal: para as faltas amparadas por leis, como licenças por gestação, nojo, gala, doação de sangue e serviço militar;

- compulsório: devido ao impedimento ao trabalho por prisão ou outro motivo que restringe a chegada ao local de trabalho (SANTI et al. 2017).

A Organização Internacional do Trabalho (OIT) define absenteísmo-doença como a "ausência ao trabalho decorrente de uma incapacidade do indivíduo, exceto por gestação ou prisão", atribuído a uma doença, ou lesão acidental, ou incapacitante, ou como medida para evitar a propagação de doenças transmissíveis (UFABC, 2019).

Estudos evidenciam que o absenteísmo por motivo de doença é um fenômeno crescente que gera custos elevados diretos e indiretos para a sociedade. Ele deve ser entendido como resultado dos determinantes sociais de saúde da população, do qual fazem parte os trabalhadores e suas respectivas condições de trabalho. Ademais, a ausência do trabalho por motivo de doença impacta negativamente o trabalhador em gozo de licença médica, trazendo-lhe sofrimento moral, sobrecarga ao nível familiar - decorrente da redução dos rendimentos - e, processos de culpabilidade por parte do gestor e da própria sociedade, nesse último caso, dando a impressão de que o trabalhador adoece e se afasta das atividades profissionais simplesmente porque quer (FIGUEIREDO, 2019).

Desse modo, na área de ensino, os afastamentos por longos períodos dos servidores da sala de aula, prejudicam ainda mais a si, pois os leva a questionar sobre sua condição como profissional e sua relação com os alunos. O mesmo pode se dizer dos alunos, sobretudo os do Ensino Médio Integrado, pois cada professor possui uma maneira de estabelecer vínculos, seja pela forma de construir o conhecimento ou pela motivação em sala de aula, visto que este vínculo é interrompido, podendo gerar uma instabilidade tanto para os alunos quanto para o docente (CODO; VASQUES-MENEZES, 2000; DALCIN; CARLOTTO, 2017).

\section{MATERIAL E MÉTODOS}

Trata-se de uma pesquisa quali-quantitativa, de análise bibliográfica e de caráter exploratório. No tocante a pesquisa qualitativa, é aquela em que não há preocupação com dados numéricos, mas sim com o aprofundamento da compreensão de um grupo social, de uma organização. De acordo com Minayo (2015), os "homo sapiens" sempre se preocuparam com o estudo da realidade. Neste contexto, busca-se analisar os estudos desenvolvidos no Programa de Mestrado em Educação Profissional e Tecnológica (ProfEPT) voltados para o absenteísmo-doença e saúde dos servidores públicos.

Quanto à pesquisa quantitativa, de acordo com Godoy (1995), evidencia-se tudo que pode ser quantificável, traduzido em número de opiniões e informações para que se possa analisar e quantificar usando a estatística. Neste caso, ela foi adotada por propiciar a análise dos dados do SIASS de 2019 do IFMT, a fim de demonstrar que os afastamentos por motivo de problemas com a saúde dos servidores na EPT, é um importante tema a ser aprofundando.

A primeira etapa deste trabalho tratou de buscar referências bibliográficas sobre absenteísmo-doença e saúde dos servidores, que desse aporte teórico de forma contextualizada ao tema estudado. Foram utilizadas bibliotecas virtuais como 
BDTD (Biblioteca Digital Brasileira de Teses e Dissertações), SCIELO (Scientific Eletronic Library Online) e Google Acadêmico.

A segunda etapa foi uma pesquisa realizada no Observatório do ProfEPT, com intuito de levantar as dissertações de mestrados dedicadas à temática do absenteísmo-doença e saúde do servidor, nas linhas de pesquisa Organização e Memórias de Espaços Pedagógicos na Educação Profissional e Tecnológica (EPT) e Práticas Educativas em Educação Profissional e Tecnológica (EPT). Para tanto, foram utilizadas as palavras-chave: "absenteísmo" e "saúde", considerando os anos de defesa de mestrado de 2019 a 2021. O critério de inclusão dos estudos foram os que apresentaram aplicação na área de saúde dos servidores públicos, assim sendo, das dezoito dissertações encontradas na plataforma, apenas duas estão relacionadas ao objeto de estudo.

$\mathrm{Na}$ terceira etapa foi realizada uma análise documental dos relatórios do SIASS de 2019 onde constam os afastamentos para tratar da própria saúde dos servidores por: local de trabalho, por CID e por cargo, com intuito de compreender a representação dos afastamentos por licença médica. Os registros desses afastamentos são de responsabilidade do Subsistema Integrado de Atenção à Saúde do Servidor Federal (SIASS), que tem por objetivo coordenar e integrar ações e programas nas áreas de assistência à saúde, perícia oficial, promoção, prevenção e acompanhamento da saúde dos servidores (Portal SIAPENet).

Sendo assim, a Unidade SIASS é responsável por homologar as licenças por motivo de saúde dos servidores no sistema SIAPE-Saúde, realizar perícias médicas/odontológicas e exames admissionais, armazenando em suas dependências os prontuários de todos os servidores atendidos na Unidade. Essa pesquisa, utilizou-se das seguintes etapas: (i) revisão da literatura; (ii) seleção de trabalhos que tratam do objeto de estudo no Observatório do ProfEPT; (iii) seleção dos materiais; (iv) leitura crítica e análise dos textos; (v) análise dos dados do SIASS.

\section{RESULTADOS E DISCUSSÃO}

Estudos que levam em questão as diversas vicissitudes sobre a saúde dos servidores, contribuem para o planejamento e qualidade dos serviços internos e externos à instituição de ensino. De acordo com Figueiredo (2019), a educação é uma área de aspectos específicos que podem atingir a saúde de seus trabalhadores, em virtude do próprio ambiente escolar e suas relações intersetoriais, gerando doenças que afetam a qualidade de vida não só no trabalho, mas também fora dele. Apesar de muitas vezes ligada diretamente à figura do professor, o âmbito da educação tem sua estrutura formada por diversos outros trabalhadores, estabelecendo uma rede de suporte para que a educação efetivamente aconteça nas instituições. Ainda segundo a autora, as transformações estruturais as quais a educação pública passou ao longo do tempo, impactam diretamente nas condições de trabalho dos servidores, influenciando tanto a sua motivação para realização de atividades como a sua produtividade, caracterizando assim, os números de absenteísmo-doença.

$\mathrm{Na}$ última década foi crescente a discussão no âmbito da Administração Pública Federal voltada para a implementação de políticas de promoção da saúde e qualidade de vida no trabalho (MARTINS et al. 2017). O Ministério do Planejamento Orçamento e Gestão (MPOG) em 2009, com o intuito de regulamentar a Política de Atenção à Saúde e Segurança do Trabalho do Servidor Público Federal (PASS), institui o Subsistema Integrado de Atenção à Saúde do Trabalhador (SIASS). As 
unidades SIASS, presentes em todo o país, têm a função de coordenar ações e programas nas áreas de assistência à saúde, perícia oficial, promoção, prevenção e vigilância da saúde dos servidores (BRASIL, 2009).

No entanto, Figueiredo (2019) destaca que ao longo do tempo, vem ocorrendo a dissolução de compromissos governamentais importantes em torno do modelo da saúde do trabalhador. Mesmo com avanços, nota-se a necessidade de uma maior articulação com os princípios que norteiam a saúde do trabalhador, e o desenvolvimento de ações efetivas de vigilância e assistência com foco na prevenção e promoção da saúde, conforme discriminado na PASS. Nesse sentido, os indicadores de afastamento por problemas de saúde dos servidores são fontes de informações para o planejamento e efetivação de qualquer ação de saúde.

Desse modo, esta pesquisa buscou interpretar a representação dos afastamentos dos servidores públicos de uma instituição pública de ensino, com base nos dados do SIASS e analisar as dissertações que tratam do tema disponíveis no Observatório do ProfEPT. O relatório do SIASS de 2019 trata-se dos números de ocorrência de afastamentos, número de servidores afastados conforme o cargo exercido e, o grupo de doenças conforme a CID 10 que mais gerou licenças médicas. Desta maneira os dados de afastamento dos servidores constam neste estudo como fonte de informações para embasar e reforçar que a temática pode ser uma opção de pesquisa para os estudantes que focam na EPT.

Os dados do Gráfico 1, indicam que 191 servidores docentes e 223 técnicos administrativos se afastaram em 2019 , sendo os TAES o segmento profissional no âmbito do IFMT, com maior número de afastamento - computado 370 ocorrências e, os docentes 290. Desse modo, proporcionalmente, obtém-se que $44 \%$ das ocorrências de afastamento por acometimento à saúde, ocorreram com docentes e $56 \%$ com Técnicos Administrativos.

Os dados também indicam que para todos os cargos demonstrados no gráfico 1, alguns servidores se afastaram mais de uma vez ao longo de 2019, visto que o número total de afastamento por licença médica é maior que o número de servidores afastados. Neste contexto, era esperado um maior número de casos de afastamento com docentes, visto ser este o segmento com o maior número de profissionais na instituição, porém de acordo com o gráfico 1, não foi constatada essa hipótese. Nesta perspectiva, Figueiredo (2019) constatou em uma outra instituição de ensino que:

[O] cargo de técnico-administrativo da instituição apresentou relação com menos dias de afastamento, o que converge com os resultados de Duração Média de Licenças (DML). Porém, em relação a frequência de eventos, nota-se um maior número de técnicos-administrativos se afastando por motivo de doença. Conclui-se que os técnicos-administrativos apresentam maior número de eventos de afastamentos, mas os docentes permanecem mais dias úteis afastados. Essa diferença de frequência e quantidade de dias pode estar relacionada às distintas características que as categorias apresentam, levando em consideração que o regime de trabalho e as carreiras são descritas em leis diferentes. (Pág.24).

Desse modo, os dados que a autora apresenta, relacionam-se com a realidade do IFMT em 2019, uma vez que de acordo com os dados observados diretamente no relatório do SIASS, docentes apresentaram maior número de dias afastados que os TAEs. 
GRÁFICO 1 - Número de casos de afastamentos, número de servidores afastados e percentual de casos de afastamentos de servidores docentes e técnicos administrativos em 2019.

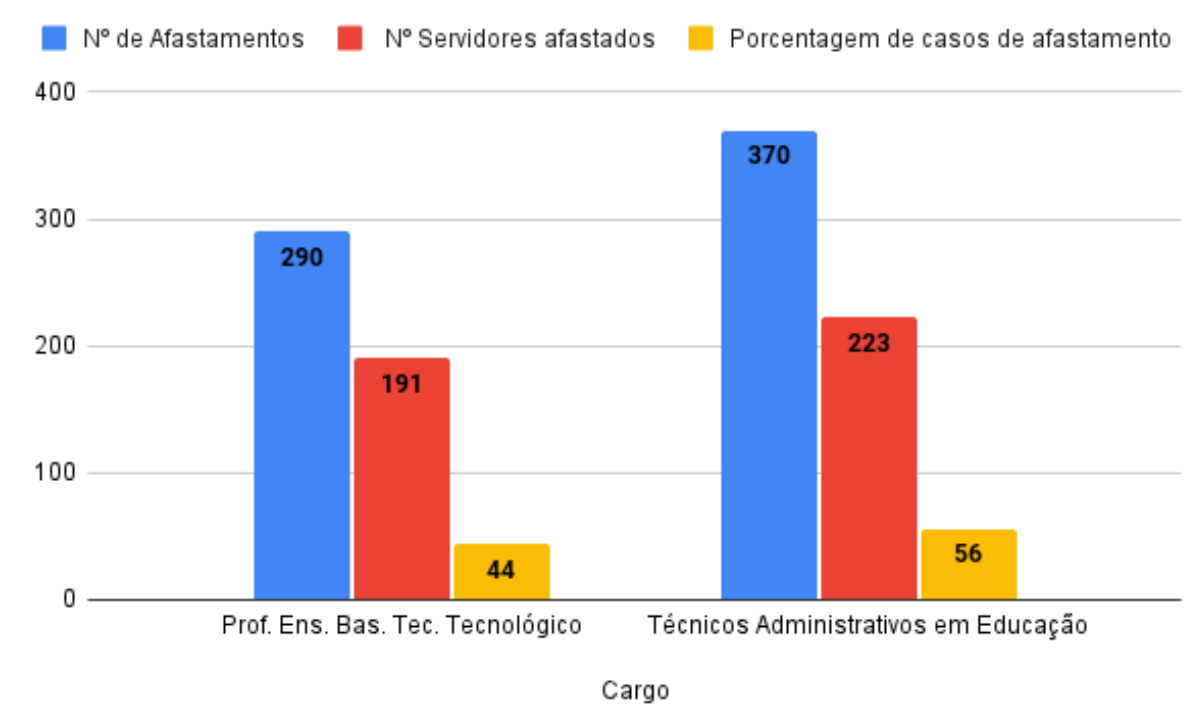

Fonte: Portal SIAPENet, registros de 01/01 a 31/12 de 2019.

O Gráfico 2 representa o número de ocorrências de afastamento por grupo de doenças, conforme os Códigos de doenças da CID 10 (Quadro 1). Consta que os grupos de doenças da CID 10 que mais geraram afastamentos dos servidores foram, nesta ordem: o F00-F99 - transtornos mentais e comportamentais; o Z00Z99 - Fatores que influenciam o estado de saúde e o contato com os serviços de saúde; e o M00-M99 - Doenças do sistema osteomuscular e do tecido conjuntivo. De acordo com os dados observados diretamente no relatório do SIASS, as doenças descritas nesses três grupos foram as causas do afastamento de cento e doze, oitenta e dois e trinta e um servidores, respectivamente.

GRÁFICO 2 - Número de afastamento por Grupo de Doenças conforme os Códigos da CID 10



Fonte: Portal SIAPENet, registros de 01/01 a 31/12 de 2019. 
Os dados encontrados nesta pesquisa assemelham-se com outros estudos. No artigo de revisão "Absenteísmo-doença no serviço público brasileiro: uma revisão integrativa da literatura" de Santi et al. (2017), os transtornos mentais e comportamentais" (TMC) surgiu como a primeira causa de absenteísmo-doença em cinco dos artigos analisados; a segunda em três artigos; e apenas em um artigo não esteve entre as primeiras causas. Além disso, os autores concluem que, a ocorrência de transtornos mentais e comportamentais e, doenças osteomusculares são as causas de absenteísmo-doença em servidores públicos, independentemente de sua lotação ou esfera administrativa, o que reflete a sua vulnerabilidade a tais agravos.

No gráfico 2, além dos inúmeros casos contidos nos grupos de doenças de $\mathrm{K}$ até $\circ \mathrm{H}$, destaca-se que o Q00-Q99 - Malformações congênitas, deformidades e anomalias cromossômicas (Quadro 1), é o grupo que contém menor ocorrência de afastamentos, correspondendo a dois casos, com dois servidores.

QUADRO 1 - Grupos de doenças conforme os Códigos da CID 10

\begin{tabular}{|l|l|}
\hline \multicolumn{1}{|c|}{ CID 10 } & \multicolumn{1}{|c|}{ Grupos de doenças conforme o Código Internacional de Doenças } \\
\hline A00-B99 & Algumas doenças infecciosas e parasitárias \\
\hline C00-D48 & Neoplasias (tumores) \\
\hline F00-F99 & Transtornos mentais e comportamentais \\
\hline H00-H59 & Doenças do olho e anexos. \\
\hline H60-H95 & Doenças do ouvido e da apófise mastoide. \\
\hline I00-199 & Doenças do aparelho circulatório. \\
\hline J00-J99 & Doenças do aparelho respiratório. \\
\hline K00-K93 & Doenças do aparelho digestivo. \\
\hline M00-M99 & Doenças do sistema osteomuscular e do tecido conjuntivo. \\
\hline N00-N99 & Doenças do aparelho geniturinário. \\
\hline O00-O99 & Gravidez, parto e puerpério. \\
\hline Q00-Q99 & Malformações congênitas, deformidades e anomalias cromossômicas. \\
\hline R00-R99 & $\begin{array}{l}\text { Sintomas, sinais e achados anormais de exames clínicos e de } \\
\text { laboratório não classificados em outra parte. }\end{array}$ \\
\hline S00-T98 & $\begin{array}{l}\text { Lesões, envenenamento e algumas outras consequências de causas } \\
\text { externas. }\end{array}$ \\
\hline Z00-Z99 & $\begin{array}{l}\text { Fatores que influenciam o estado de saúde e o contato com os } \\
\text { serviços de saúde. }\end{array}$ \\
\hline
\end{tabular}

Fonte: Elaborado pelos autores (2021) com base no Portal Médico do Brasil, CID 10 - MedicinaNET

Ainda assim, em um outro estudo realizado por Lemos et al. (2018) com profissionais da saúde do Distrito Federal, apontou que os transtornos mentais e comportamentais foram os motivos clínicos que mais afastaram do trabalho esses servidores, seguido das doenças osteomusculares e do tecido conjuntivo. Constatou-se também que os transtornos mentais e as doenças osteomusculares representaram as principais causas de adoecimento em todos os estratos das categorias profissionais avaliadas. Em síntese, ficou evidente nos estudos apresentados, que de forma geral os transtornos mentais e as doenças osteomusculares são os principais causadores de absenteísmo-doença nos diferentes locais de trabalho. 
Tratando-se de servidores públicos federais de ensino, Figueiredo (2019) buscou conhecer o perfil dos afastamentos e, também evidenciou que os transtornos mentais e comportamentais se destacam como as doenças que mais os afastam. Dentro da rede federal a categoria de professores é a mais afetada em virtude da relação com o ambiente escolar, ritmo excessivo e a organização estrutural do trabalho. Posto isto, é possível que no IFMT em 2019, mais professores se afastaram por problemas relacionados à saúde mental do que os servidores TAEs.

Analisar os dados do SIASS de 2019 e os estudos desenvolvidos no âmbito do ProfEPT, foram uma etapa importante para responder o objetivo deste trabalho, que visa analisar de que forma os estudos focados no absenteísmo-doença e saúde dos servidores públicos federais têm sido abordados.

Para tanto, nos quadros 2 e 3 abaixo, constam as dezoito dissertações do ProfEPT levantadas no observatório do programa, que aborda o tema saúde; sua abordagem metodológica; os principais autores; os principais resultados e, o produto educacional. Os estudos foram ordenados conforme maior relação ao tema saúde dos servidores e, divididos pelas duas linhas de pesquisa: Organização e Memórias de Espaços Pedagógicos na EPT (Quadro 2) e Práticas Educativas em EPT (Quadro $3)$.

Contudo, das cinco dissertações desenvolvidas na linha de pesquisa "Organização e Memórias de Espaços Pedagógicos na EPT", onde os autores se ocuparam de temas cujos objetivos estavam relacionados à saúde, apenas duas abordam a "saúde do servidor". Dessas, a de autoria de Antunes (2019), apresentada no quadro 2, traz resultados importantes, porém não apresenta dados de afastamentos. $\mathrm{O}$ autor aponta o desconhecimento dos servidores sobre o tema, revelando a necessidade de mais estudos que aprofundem sobre a saúde do servidor. Ainda assim, no intuito de contribuir com o fortalecimento das ações em educação em saúde, o autor propôs como produto educacional um material textual, com foco na sensibilização da saúde no local de trabalho.

Outra dissertação que também atende ao objetivo deste trabalho é sobre a saúde vocal dos Servidores Docentes da EPT, a autora Midorikawa (2020), buscou conhecer a condição de voz dos professores no âmbito do IFPR - Campus Curitiba. Considera-se de muita relevância esse tema, visto que a voz é o principal instrumento de trabalho do professor. Dentre as queixas dos servidores, a autora constatou como as principais: disfonias e afonias - problemas que podem ser causados pela acústica das salas. Além disso, foram verificadas as questões referentes ao cansaço vocal e a necessidade de "erguer a voz" em sala de aula, como consequência ao ruído presente no ambiente laboral. Como medida de intervenção o autor propôs um Manual de Saúde Vocal com intuito de compartilhar dicas e práticas cotidianas de cuidados com a voz e, informações sobre a atenção à saúde do servidor pertencente à Rede Federal de Educação Profissional, Científica e Tecnológica (RFEPCT), de forma que possa ser utilizado futuramente como um material de apoio aos professores de toda a rede.

Conforme a CID 10, os problemas com a voz pertencem ao grupo de doenças R00-R99 - Sintomas, sinais e achados anormais de exames clínicos e de laboratório, não classificados em outra parte. Constata-se que esse grupo não está entre as situações que mais afetaram os servidores do IFMT em 2019, conforme gráfico 1. Desta maneira, depreende-se que as ações de saúde em torno dos acometimentos à saúde vocal dos servidores podem ser tratadas principalmente com foco nas áreas de promoção e prevenção da saúde. 
Para Viapiana et al., (2018), as doenças relacionadas à saúde mental têm adquirido crescente relevância científica nos últimos anos. Isso faz do estudo de Antunes (2019) um passo importante sobre a saúde dos servidores públicos federais de ensino, uma vez que no IFMT ficou constatado o grande número de casos de afastamentos pelo Grupo de doenças F00-F99 - transtornos mentais e comportamentais (Gráfico 2).

QUADRO 2 - Dissertações defendidas na linha de pesquisa: Organização e Memórias de Espaços Pedagógicos na EPT de 2019 a 2021.

\begin{tabular}{|c|c|c|c|}
\hline $\begin{array}{c}\text { TÍTULO/ } \\
\text { INSTITUIÇÃO/ } \\
\text { AUTOR/ ANO }\end{array}$ & $\begin{array}{c}\text { METODOLOGIA / } \\
\text { PRINCIPAIS } \\
\text { REFERÊNCIAS }\end{array}$ & PRINCIPAIS RESULTADOS & $\begin{array}{l}\text { PRODUTO } \\
\text { EDUCACIONAL }\end{array}$ \\
\hline $\begin{array}{l}\text { SAÚDE MENTAL } \\
\text { DO SERVIDOR } \\
\text { PÚBLICO } \\
\text { FEDERAL NA } \\
\text { EDUCAÇÃO } \\
\text { PROFISSIONAL } \\
\text { E } \\
\text { TECNOLÓGICA: } \\
\text { UM ENFOQUE } \\
\text { TEÓRICO- } \\
\text { PRÁTICO A } \\
\text { PARTIR DO } \\
\text { CÂMPUS } \\
\text { PINHAIS / IFPR / } \\
\text { Antunes (2019). }\end{array}$ & $\begin{array}{l}\text { Pesquisa } \\
\text { exploratória com } \\
\text { abordagem } \\
\text { qualitativa. } \\
\text { Revisão } \\
\text { bibliográfica e } \\
\text { documental com } \\
\text { aplicação de } \\
\text { questionário aos } \\
\text { servidores do } \\
\text { Câmpus Pinhais. } \\
\text { Principais autores: } \\
\text { CARVALHO, A. M. } \\
\text { P } \\
\text { DEJOURS, C } \\
\text { DINIZ, A. S. B } \\
\text { FREITAS, R. C. O. } \\
\text { GRAMSCI, A } \\
\text { MENDES, A. M. }\end{array}$ & $\begin{array}{l}\text { - Apontaram a desinformação do } \\
\text { servidor sobre o tema e a pouca } \\
\text { discussão na administração } \\
\text { federal. } \\
\text { - Necessidade de fortalecer a } \\
\text { inclusão de ações voltadas à } \\
\text { educação em saúde e ao } \\
\text { estímulo dos fatores de proteção } \\
\text { da saúde com melhoria dos } \\
\text { ambientes, da organização e do } \\
\text { processo de trabalho } \\
\text { - O contato com o folder gerou } \\
\text { questionamentos sobre: dados } \\
\text { referentes a quantificação de } \\
\text { servidores afastados do } \\
\text { trabalho, os principais } \\
\text { transtornos que levam a } \\
\text { incapacidade laboral e como } \\
\text { são tratadas essas } \\
\text { problemáticas pela; } \\
\text { - Revela a necessidade de } \\
\text { novos estudos que subsidiem } \\
\text { discussões relacionadas ao } \\
\text { tema saúde do trabalhador, com } \\
\text { intuito de investigar } \\
\text { determinantes do sofrimento } \\
\text { mental e suas causas. } \\
\text { - Até o momento na história } \\
\text { dessa instituição nunca havia } \\
\text { sido realizado um estudo que } \\
\text { levantasse a discussão do } \\
\text { assunto entre os servidores. } \\
\text { - Lacunas: os servidores são } \\
\text { constantemente alvejados por } \\
\text { notícias da mídia que fragilizam } \\
\text { a imagem do seu trabalho diante } \\
\text { dos cidadãos. Esse tipo de } \\
\text { sofrimento não é encontrado no } \\
\text { senso comum tano } \\
\text { explicitamente, fazendo-se } \\
\text { urgente uma reflexão contextual } \\
\text { sobre o assunto. } \\
\text { - Neste estudo não foram } \\
\text { utilizados dados do afastamento } \\
\text { de servidores SIASS/UTFPR - }\end{array}$ & 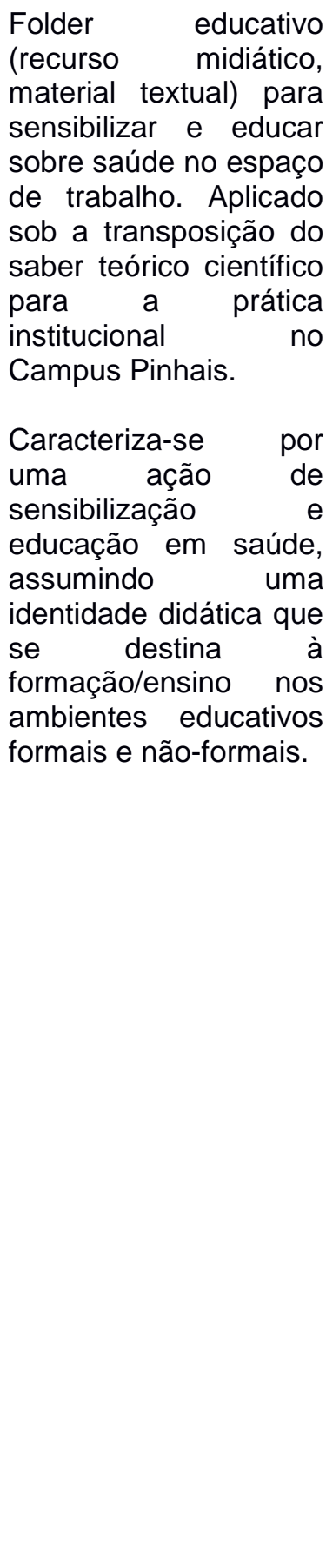 \\
\hline
\end{tabular}




\begin{tabular}{|c|c|c|c|}
\hline & & $\begin{array}{l}\text { IFPR /Curitiba-PR sob } \\
\text { argumentação de que o sistema } \\
\text { SIAPE - Saúde não informa as } \\
\text { licenças para tratamento de } \\
\text { saúde por CID. }\end{array}$ & \\
\hline $\begin{array}{l}\text { SAÚDE VOCAL } \\
\text { DOS } \\
\text { SERVIDORES } \\
\text { DOCENTES DA } \\
\text { EDUCAÇÃO } \\
\text { PROFISSIONAL } \\
\text { E } \\
\text { TECNOLÓGICA: } \\
\text { CONDIÇÕES DE } \\
\text { VOZ DOS } \\
\text { PROFESSORES } \\
\text { NO ÂMBITO DO } \\
\text { IFPR - CAMPUS } \\
\text { CURITIBA/ IFPR / } \\
\text { Midorikawa } \\
\text { (2020) }\end{array}$ & $\begin{array}{l}\text { Pesquisa mista, a } \\
\text { qual, conforme } \\
\text { Sampieri et al. } \\
\text { (2013, p. 548), } \\
\text { "envolve um } \\
\text { processo de } \\
\text { coleta, análise e } \\
\text { vínculo de dados } \\
\text { quantitativos e } \\
\text { qualitativos em um } \\
\text { mesmo estudo ou } \\
\text { uma série de } \\
\text { pesquisas para } \\
\text { responder uma } \\
\text { formulação do } \\
\text { problema") A } \\
\text { coleta e análise } \\
\text { dos dados foi } \\
\text { realizada de } \\
\text { acordo com } \\
\text { Desenho } \\
\text { Exploratório } \\
\text { Sequencial } \\
\text { (DEXPLOS) } \\
\text { A metodologia } \\
\text { para a coleta de } \\
\text { dados desta } \\
\text { pesquisa partiu da } \\
\text { investigação das } \\
\text { queixas de } \\
\text { problemas vocais } \\
\text { dos docentes e da } \\
\text { verificação do } \\
\text { ambiente laboral } \\
\text { em que estes } \\
\text { estão inseridos. } \\
\text { Principais autores: } \\
\text { SAVIANI, D.; } \\
\text { TEIXEIRA, L. C.; } \\
\text { ZANATTA, O. A.; } \\
\text { KUENZER, A. Z.; } \\
\text { CIAVATTA, M. }\end{array}$ & $\begin{array}{l}\text { - As principais queixas relatadas } \\
\text { são as disfonias e afonias, } \\
\text { problemas estes que podem } \\
\text { encontrar na acústica das salas; } \\
\text { - Além disso, foram verificadas } \\
\text { as questões referentes ao } \\
\text { cansaço vocal e necessidade de } \\
\text { "erguer a voz" em sala de aula, } \\
\text { como consequência ao ruído } \\
\text { presente no ambiente laboral. } \\
\text { - Ressalta-se que, apesar do } \\
\text { baixo alcance percebido quando } \\
\text { da aplicação do manual de } \\
\text { saúde vocal, de maneira geral, } \\
\text { verificou-se que, para a maioria } \\
\text { dos professores que } \\
\text { participaram da etapa de } \\
\text { avaliação do produto, o material } \\
\text { proposto obteve resultados } \\
\text { positivos. }\end{array}$ & $\begin{array}{l}\text { SAÚDE VOCAL EM } \\
\text { PROFESSORES } \\
\text { EBTT } \\
\text { (Livro / Manual / Guia } \\
\text { Texto de Apoio) } \\
\text { Registro: ISBN: 978- } \\
65-00-13328-8 \\
\text { Manual de Saúde } \\
\text { Vocal teve por intuito o } \\
\text { compartilhamento de } \\
\text { dicas e práticas } \\
\text { cotidianas de cuidados } \\
\text { com a voz, e } \\
\text { informações sobre a } \\
\text { atençào à saúde do } \\
\text { servidor pertencente à } \\
\text { RFEPCT, de forma } \\
\text { que possa ser utilizado } \\
\text { futuramente como um } \\
\text { material de apoio aos } \\
\text { professores de toda a } \\
\text { RFEPCT. O produto } \\
\text { educacional fora } \\
\text { delimitado com foco } \\
\text { principal nas áreas de } \\
\text { promoção e prevenção } \\
\text { da saúde. }\end{array}$ \\
\hline $\begin{array}{l}\text { A PERCEPÇÃO } \\
\text { DE QUEM } \\
\text { CUIDA: SAÚDE } \\
\text { MENTAL DE } \\
\text { ESTUDANTES } \\
\text { SOB A ÓTICA } \\
\text { DAS EQUIPES } \\
\text { DE SAÚDE, }\end{array}$ & $\begin{array}{l}\text { Classificam-se em } \\
\text { quanti-qualitativa, } \\
\text { tendo como } \\
\text { instrumentos de } \\
\text { coleta de dados o } \\
\text { questionário de } \\
\text { escala Likert e a } \\
\text { entrevista }\end{array}$ & $\begin{array}{l}\text { - Há necessidade de } \\
\text { aprofundamento da área de } \\
\text { saúde mental por parte dos } \\
\text { servidores, além de levar ao } \\
\text { conhecimento o Guia de } \\
\text { Educação em Saúde Mental } \\
\text { para manejo de situações } \\
\text { emergenciais, bem como da }\end{array}$ & $\begin{array}{l}\text { GUIA DE EDUCAÇÃO } \\
\text { EM SAÚDE MENTAL } \\
\text { (Livro) } \\
\text { Instruir sobre a } \\
\text { importância do termo } \\
\text { "saúde mental", bem } \\
\text { como expor }\end{array}$ \\
\hline
\end{tabular}




\begin{tabular}{|c|c|c|c|}
\hline $\begin{array}{l}\text { PEDAGÓGICA E } \\
\text { DE } \\
\text { ASSISTÊNCIA } \\
\text { ESTUDANTIL / } \\
\text { IFPB / Mousinho } \\
\text { (2021) }\end{array}$ & $\begin{array}{l}\text { semiestruturada. } \\
\text { Principais autores: } \\
\text { VALADÃO M.M } \\
\text { VIEIRA, A. M. } \\
\text { ESTANISLAU, G. } \\
\text { M.; } \\
\text { BRESSAN, R. A. }\end{array}$ & $\begin{array}{l}\text { rede externa de atenção } \\
\text { psicossocial. }\end{array}$ & $\begin{array}{l}\text { informações acerca do } \\
\text { bom acolhimento para } \\
\text { os estudantes e } \\
\text { conscientizar as } \\
\text { servidores a respeito } \\
\text { do fluxograma de } \\
\text { atendimento } \\
\text { emergencial em saúde } \\
\text { mental. }\end{array}$ \\
\hline $\begin{array}{l}\text { PROPOSTA } \\
\text { PARA } \\
\text { PROMOÇÃO DA } \\
\text { SAÚDE MENTAL } \\
\text { DISCENTE NO } \\
\text { CONTEXTO DA } \\
\text { EDUCAÇÃO } \\
\text { PROFISSIONAL } \\
\text { E } \\
\text { TECNOLÓGICA / } \\
\text { IFSP / Jorge } \\
\text { (2019) }\end{array}$ & $\begin{array}{l}\text { Trata-se de uma } \\
\text { pesquisa } \\
\text { qualitativa. Os } \\
\text { instrumentos } \\
\text { utilizados para a } \\
\text { coleta de dados } \\
\text { foram os grupos } \\
\text { focais com os } \\
\text { discentes e } \\
\text { questionários } \\
\text { online com } \\
\text { discentes e } \\
\text { docentes. } \\
\text { A análise e o } \\
\text { tratamento dos } \\
\text { dados se deram } \\
\text { por meio do } \\
\text { trabalho com eixos } \\
\text { de análise em } \\
\text { pesquisa } \\
\text { qualitativa. } \\
\\
\text { Principais autores: } \\
\text { ANTUNES, R } \\
\text { BOURDIEU, P.; } \\
\text { BROCCOLICHI, S. } \\
\text { CIAVATTA, M. } \\
\text { LOUREIRO, T. J. } \\
\text { L. } \\
\text { PEREIRA, E. A } \\
\text { RAMOS, M. } \\
\text { SANTOS, M. T } \\
\text { VIEIRA, A. G. } \\
\text { SAVIANI, D }\end{array}$ & $\begin{array}{l}\text { - Os alunos não escolheram o IF } \\
\text { por afinidade com o curso } \\
\text { técnico ou pelo EMI, mas pelo } \\
\text { ideal social e familiar, bem como } \\
\text { pela promessa de um futuro } \\
\text { promissor; } \\
\text { - Constatou-se que o primeiro } \\
\text { ano do EMl se configura como } \\
\text { um momento crítico para os } \\
\text { estudantes. - adaptação ao novo } \\
\text { contexto escolar, de dificuldades } \\
\text { e angústias } \\
\text { - Os estudantes revelaram um } \\
\text { sentimento de fracasso ligado } \\
\text { ao baixo rendimento escolar que } \\
\text { experienciam no primeiro ano do } \\
\text { EMl; No entanto, EMI é } \\
\text { percebido de forma positiva } \\
\text { pelos alunos, pois, a partir da } \\
\text { lógica capitalista, acreditam que } \\
\text { o sucesso é obtido pelo esforço } \\
\text { e dedicação próprios; } \\
\text { - Constatou-se a grande } \\
\text { quantidade de trabalho escolar, } \\
\text { aos quais são submetidos os } \\
\text { alunos do EMl; } \\
\text { - Revelou-se ainda o sofrimento } \\
\text { psíquico do educador. A forma } \\
\text { em que está estruturado o } \\
\text { currículo pode gerar situações } \\
\text { de estresse e sofrimento tanto } \\
\text { para discentes como para } \\
\text { docentes. } \\
\text { - O sofrimento psíquico dos } \\
\text { estudantes está atrelado a } \\
\text { outros fatores para além do } \\
\text { excesso de atividades no EMl, } \\
\text { se pensarmos que são filhos da } \\
\text { classe trabalhadora, seres } \\
\text { sociais; têm a percepção de } \\
\text { precarização do trabalho, } \\
\text { sofrem o mal estar geral da } \\
\text { sociedade mediada pelo capital. } \\
\text { - Lacunas para pesquisas } \\
\text { futuras. Quem são estes alunos } \\
\text { que mais sofrem? A intensidade } \\
\text { desse sofrimento é maior no no } \\
\text { aluno de qual gênero? A renda } \\
\text { familiar destes alunos é menor }\end{array}$ & 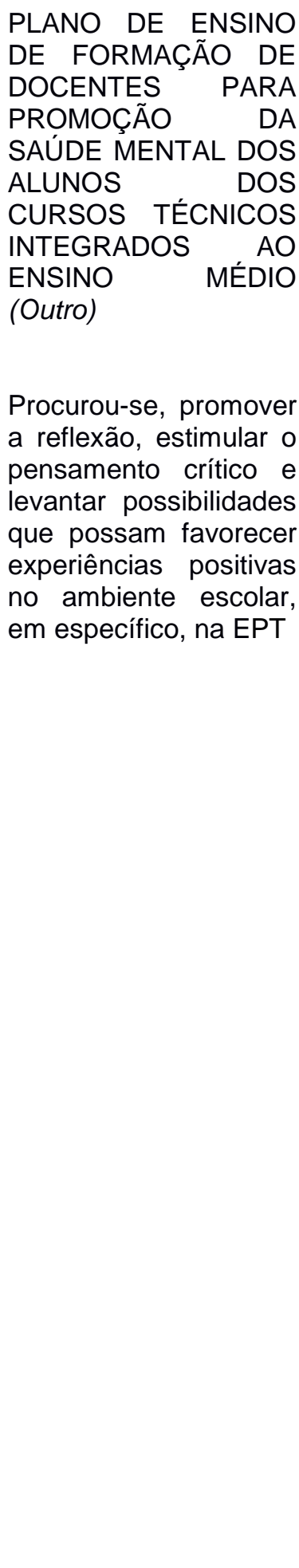 \\
\hline
\end{tabular}




\begin{tabular}{|c|c|c|c|}
\hline & & $\begin{array}{l}\text { que a média? Entre os jovens } \\
\text { da classe trabalhadora mais } \\
\text { precarizada estes sofrimentos } \\
\text { são mais agudos/latentes? } \\
\text { Quem são esses professores } \\
\text { que atuam com estes alunos? } \\
\text { Os docentes do EMI dos IFs } \\
\text { trabalham comprometidos com a } \\
\text { superação da dualidade } \\
\text { histórica da escola? }\end{array}$ & \\
\hline $\begin{array}{l}\text { SEGURANÇA E } \\
\text { SAÚDE DO } \\
\text { TRABALHO EM } \\
\text { LABORATÓRIOS } \\
\text { DE ENSINO: } \\
\text { PROPOSTA DE } \\
\text { UM MANUAL } \\
\text { PARA } \\
\text { PREVENÇÃO DE } \\
\text { RISCOS E DE } \\
\text { ACIDENTES / } \\
\text { IFRN / Maia } \\
\text { (2019) } \\
\text { * Dissertação não } \\
\text { está disponível no } \\
\text { Observatório }\end{array}$ & $\begin{array}{l}\text { A pesquisa foi de } \\
\text { natureza aplicada } \\
\text { de caráter } \\
\text { exploratório e } \\
\text { descritivo. } \\
\text { O método para a } \\
\text { coleta de dados foi } \\
\text { de cunho } \\
\text { qualitativo e } \\
\text { quantitativo, } \\
\text { utilizando } \\
\text { questionários com } \\
\text { perguntas } \\
\text { fechadas e } \\
\text { abertas. }\end{array}$ & $\begin{array}{l}\text { Os resultados encontrados } \\
\text { foram que o manual elaborado } \\
\text { aborda a temática da segurança } \\
\text { e saúde do trabalho de forma } \\
\text { clara, com uma linguagem } \\
\text { objetiva e de fácil entendimento, } \\
\text { sendo adequado à finalidade } \\
\text { que se destina. }\end{array}$ & 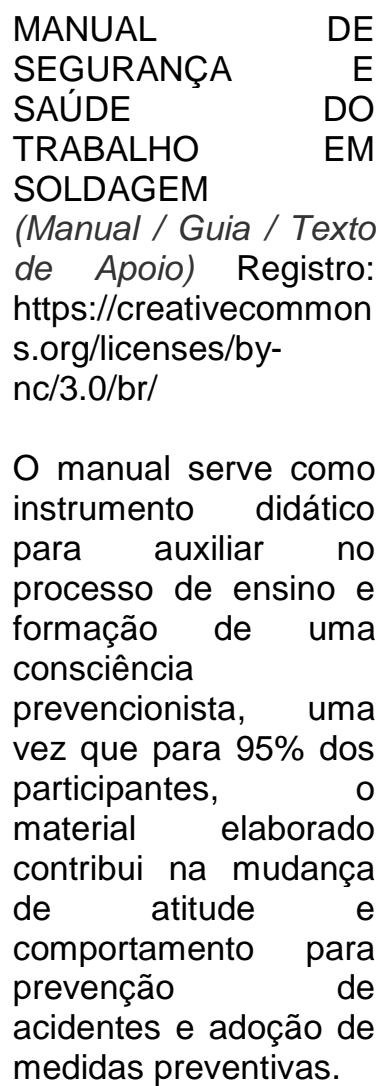 \\
\hline $\begin{array}{l}\text { TOTAL DE } \\
\text { ESTUDOS }\end{array}$ & \multicolumn{3}{|l|}{05} \\
\hline
\end{tabular}

Fonte: IFTM - Observatório do ProfEPT.(2021)

Da mesma forma, os demais estudos que constam no quadro 3 - ao todo 13 dissertações - foram realizados na linha de pesquisa "Práticas Educativas na EPT". Os autores se ocuparam de discutir assuntos relevantes, que abrangem questões que envolvem a segurança do trabalho, educação em saúde, prevenção de suicídios, promoção da saúde mental discente, educação física e qualidade de vida, saúde do trabalhador, e ainda proposta de plano de ensino para capacitar o servidor docente sobre a promoção da saúde em sala de aula. Com isso, verifica-se que todas essas dissertações foram realizadas considerando a perspectiva do aluno, com propostas de produtos educacionais para promover mudanças em sala de aula. Mesmo esses estudos não tratando diretamente da saúde do servidor e não estando diretamente ligadas ao tema deste estudo, percebe-se que autores como Pacheco (2019), Gomes (2020) e Souza (2020a), salientam a necessidade de agregar o tema saúde tratados juntos aos discentes, também aos servidores da instituição, pois 
consideram ser mais efetiva a sensibilização sobre saúde no âmbito escolar. Por fim, é importante ressaltar que três dissertações não atendem ao objetivo deste trabalho cujos temas são: "Do humor ao aprendizado: a utilização de memes como ferramenta pedagógica para o ensino da educação física", "Eu lembro como se fosse hoje: Memórias do curso técnico em agente comunitário de saúde" e, "A língua brasileira (LIBRAS) de sinais no curso técnico de enfermagem do IFNMG", mas por constar as palavras-chave utilizadas na pesquisa no Observatório, estão sendo contabilizadas no quadro 3.

QUADRO 3 - Dissertações defendidas na linha de pesquisa: Práticas Educativas na EPT de 2019 a 2021.

\begin{tabular}{|c|c|c|c|}
\hline $\begin{array}{c}\text { TÍTULO/ } \\
\text { INSTITUIÇÃO/ } \\
\text { AUTOR/ ANO }\end{array}$ & $\begin{array}{l}\text { METODOLOGIA/ } \\
\text { PRINCIPAIS } \\
\text { REFERÊNCIAS }\end{array}$ & PRINCIPAIS RESULTADOS & $\begin{array}{c}\text { PRODUTO } \\
\text { EDUCACIONAL }\end{array}$ \\
\hline $\begin{array}{l}\text { AVALIE SAÚDE: } \\
\text { UMA PROPOSTA } \\
\text { EDUCACIONAL } \\
\text { TECNOLÓGICA } \\
\text { VOLTADA PARA } \\
\text { OS DOCENTES } \\
\text { DE EDUCAÇÃO } \\
\text { FÍSICA DA } \\
\text { EDUCAÇÃO } \\
\text { PROFISSIONAL } \\
\text { E IFPR / Souza } \\
\text { TECNOLÓGICA / } \\
\text { IFPR }\end{array}$ & $\begin{array}{l}\text { Abordagem } \\
\text { qualitativa, utiliza o } \\
\text { método exploratório, } \\
\text { tendo como } \\
\text { instrumento de } \\
\text { coleta de dados o } \\
\text { questionário aberto. } \\
\text { Principais autores: } \\
\text { FRIGOTTO, G.; } \\
\text { CIAVATTA, M.; } \\
\text { RAMOS, M.; } \\
\text { LEITE, J. C. C.; } \\
\text { PACHECO, E.; } \\
\text { LEMOS JÚNIOR, } \\
\text { W.; } \\
\text { ESTRELA, S. DA C. }\end{array}$ & $\begin{array}{l}\text { Os recursos tecnológicos } \\
\text { educacionais podem contribuir } \\
\text { com a Educação Física Escolar, } \\
\text { na autonomia e potencializando } \\
\text { a aprendizagem motora, } \\
\text { cognitiva, social e emocional } \\
\text { dos estudantes. Quanto ao } \\
\text { aplicativo como ferramenta } \\
\text { pedagógica, foram identificadas } \\
\text { características favoráveis } \\
\text { referentes à praticidade, } \\
\text { aplicabilidade, funcionalidade, } \\
\text { questões visuais } \\
\text { contribuições para o ensino e } \\
\text { aprendizagem. }\end{array}$ & $\begin{array}{l}\text { AVALIE SAÚDE } \\
\text { (Aplicativo } \\
\text { (smartphone)) } \\
\text { Buscou-se } \\
\text { desenvolver } \\
\text { dispositivo um } \\
\text { facilitar para } \\
\text { armazenamento } \\
\text { acompanhamento } \\
\text { pelo professor dos } \\
\text { resultados alcançados } \\
\text { por cada estudante. }\end{array}$ \\
\hline $\begin{array}{l}\text { REALIZAÇÃO DA } \\
\text { SIPAT EM UMA } \\
\text { UNIDADE DA } \\
\text { REDE FEDERAL } \\
\text { DE EDUCAÇÃO, } \\
\text { CIÊNCIA E } \\
\text { TECNOLOGIA } \\
\text { COMO FORMA } \\
\text { DE PROMOVER } \\
\text { A SEGURANÇA } \\
\text { DO TRABALHO } \\
\text { NO ENSINO } \\
\text { TÉCNICO E } \\
\text { TECNOLÓGICO / } \\
\text { IFMT / Gomes } \\
\text { (2020) }\end{array}$ & $\begin{array}{l}\text { A abordagem da } \\
\text { pesquisa adotada é } \\
\text { a mista (quali- } \\
\text { quantitativa). } \\
\text { Quanto à sua } \\
\text { natureza, se } \\
\text { caracteriza por ser } \\
\text { uma pesquisa } \\
\text { aplicada. } \\
\text { O instrumento } \\
\text { utilizado foi um } \\
\text { questionário on-line. } \\
\text { Principais autores: } \\
\text { FRIGOTTO, G.; } \\
\text { SAVIANI, D.; } \\
\text { ZABALLA, A. } \\
\text { VERA, L. C. R. G. } \\
\text { WILSON, J. } \\
\text { STANDING, G. } \\
\text { KAMPER, D. } \\
\text { OFFE, C. } \\
\text { ANTUNES, R. } \\
\text { MARX, K. }\end{array}$ & $\begin{array}{l}\text { - Realização do 10 SIPAT no } \\
\text { IFRO - Campus Jaru como } \\
\text { forma de promover a segurança } \\
\text { do trabalho. O evento foi } \\
\text { avaliado por meio de uma } \\
\text { pesquisa de satisfação } \\
\text { entregue aos participantes, } \\
\text { podendo ser respondido } \\
\text { anonimamente. A partir deste } \\
\text { formulário de avaliação foi } \\
\text { elaborada a cartilha. } \\
\text { - Retornando às perguntas de } \\
\text { pesquisa iniciais sobre a } \\
\text { importância de se trabalhar } \\
\text { temas voltados a prevenção, } \\
\text { confirma-se e ainda se agrega } \\
\text { a isso a necessidade de se } \\
\text { trabalhar a questão da } \\
\text { sensibilização por parte dos } \\
\text { servidores, pois notou-se que a } \\
\text { participação dos alunos se } \\
\text { sobressai em relação a dos } \\
\text { servidores do campus. }\end{array}$ & $\begin{array}{l}\text { PREVENÇÃO: UMA } \\
\text { QUESTÃO DE } \\
\text { SAÚDE E } \\
\text { SEGURANÇA } \\
\text { (Curso / Minicurso / } \\
\text { Manual / Guia / Texto } \\
\text { de Apoio) } \\
\text { - Realização do } \\
\text { Evento SIPAT no } \\
\text { IFRO. } \\
\text { - Cartilha trazendo } \\
\text { elementos } \\
\text { orientação acerca da } \\
\text { prevenção aos riscos } \\
\text { de acidentes. }\end{array}$ \\
\hline
\end{tabular}




\begin{tabular}{|c|c|c|c|}
\hline $\begin{array}{l}\text { SAÚDE DO } \\
\text { TRABALHADOR: } \\
\text { A } \\
\text { CONTRIBUIÇÃO } \\
\text { DOS } \\
\text { CONHECIMENT } \\
\text { OS EM SAÚDE } \\
\text { SOB UMA } \\
\text { PERSPECTIVA } \\
\text { AMPLIADA PARA } \\
\text { A FORMAÇÃO } \\
\text { PROFISSIONAL } \\
\text { E } \\
\text { TECNOLÓGICA } \\
\text { INTEGRADA AO } \\
\text { ENSINO MÉDIO / } \\
\text { IFES / LuZ Júnior } \\
\text { (2020) }\end{array}$ & $\begin{array}{l}\text { Pesquisa } \\
\text { participante, } \\
\text { realizada em quatro } \\
\text { etapas: análise } \\
\text { documental, } \\
\text { seleção de } \\
\text { estudantes, } \\
\text { entrevista e curso. } \\
\text { Coleta de dados por } \\
\text { meio de curso de } \\
\text { complementação ao } \\
\text { ensino sobre o tema } \\
\text { saúde. Realizou-se } \\
\text { também entrevista, } \\
\text { observação } \\
\text { participante, roda de } \\
\text { conversa. } \\
\text { Abordagem } \\
\text { qualitativa. } \\
\text { Principais autores: } \\
\text { BAUMAN, Z. } \\
\text { SENNETT, R. } \\
\text { ANTUNES, R. }\end{array}$ & $\begin{array}{l}\text { - Constatou-se que o tema } \\
\text { saúde quando empregado } \\
\text { pelos professores pode auxiliar } \\
\text { os discentes a compreenderem } \\
\text { as contradições dos modos de } \\
\text { vida e produção. Constatou-se } \\
\text { que os discentes não interligam } \\
\text { as mudanças no mundo do } \\
\text { trabalho com o adoecimento do } \\
\text { trabalhador. Após o curso, } \\
\text { percebeu-se por meio de relato } \\
\text { dos discentes que a visão } \\
\text { destes foi ampliada, } \\
\text { estabelecendo criticidade ao } \\
\text { "mercado de trabalho" e } \\
\text { pontuando questões } \\
\text { prejudiciais à sua saúde. }\end{array}$ & 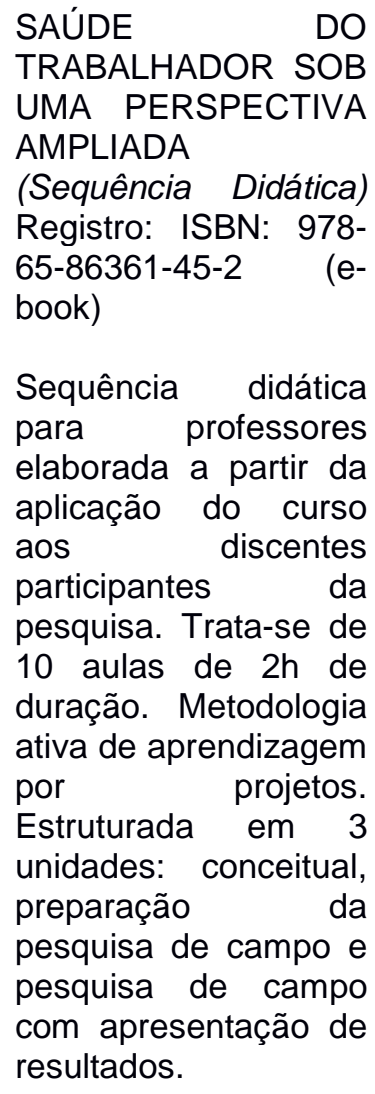 \\
\hline $\begin{array}{l}\text { ESTRATÉGIAS } \\
\text { DE PRÁTICAS } \\
\text { DE EDUCAÇÃO } \\
\text { EM SAÚDE } \\
\text { PARA A } \\
\text { FORMAÇÃO } \\
\text { INTEGRAL DE } \\
\text { DISCENTES } \\
\text { DOS CURSOS } \\
\text { TÉCNICOS } \\
\text { INTEGRADOS } \\
\text { DO INSTITUTO } \\
\text { FEDERAL } \\
\text { FARROUPILHA - } \\
\text { CAMPUS } \\
\text { JAGUARI / } \\
\text { IFFarroup / Souza } \\
\text { (2020a) }\end{array}$ & $\begin{array}{l}\text { Natureza qualitativa. } \\
\text { Coleta de dados } \\
\text { realizada através de } \\
\text { questionário } \\
\text { aplicado aos } \\
\text { discentes do } \\
\text { primeiro e terceiro } \\
\text { anos do Curso } \\
\text { Técnico Integrado } \\
\text { em Sistemas de } \\
\text { Energia Renovável, } \\
\text { docentes do curso e } \\
\text { profissionais da } \\
\text { Assistência } \\
\text { Estudantil. } \\
\text { Pesquisa-ação } \\
\text { através da } \\
\text { observação direta } \\
\text { extensiva } \\
\text { Principais autores: } \\
\text { FRIGOTTO, G.; } \\
\text { GRAMSCI, A.; } \\
\text { MELO, J.A.; } \\
\text { CANDEIAS, N. M. } \\
\text { F.; CIAVATTA, M. }\end{array}$ & $\begin{array}{l}\text { Foi possível compreender as } \\
\text { percepções da comunidade } \\
\text { acadêmica sobre as ações e } \\
\text { serviço de saúde do campus e } \\
\text { sua relação com permanência, } \\
\text { rendimento escolar e qualidade } \\
\text { de vida. Além disso, } \\
\text { constatamos a relevância em } \\
\text { articular formas de integrar o } \\
\text { trabalho em saúde dos } \\
\text { Institutos Federais, avaliar as } \\
\text { ações e serviços e mais } \\
\text { estudos dessa natureza. }\end{array}$ & 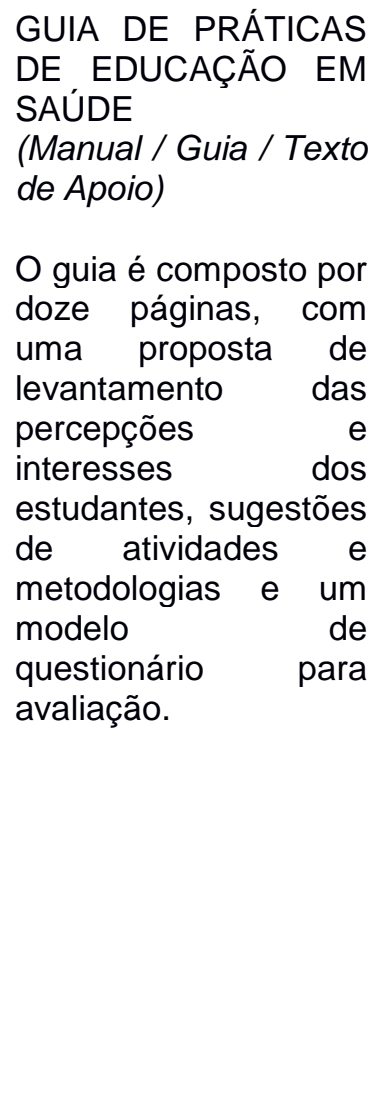 \\
\hline $\begin{array}{l}\text { A LÍNGUA } \\
\text { BRASILEIRA DE } \\
\text { SINAIS (LIBRAS) }\end{array}$ & $\begin{array}{l}\text { Estudo com } \\
\text { metodologia } \\
\text { pesquisas do tipo }\end{array}$ & $\begin{array}{l}\text { - Importante ressaltar que ainda } \\
\text { há confusão no entendimento } \\
\text { dos conceitos de deficiência }\end{array}$ & $\begin{array}{l}\text { CURSO } \\
\text { INSTRUMENTAL DE } \\
\text { LIBRAS } \quad \text { COM }\end{array}$ \\
\hline
\end{tabular}




\begin{tabular}{|c|c|c|c|}
\hline $\begin{array}{l}\text { NO CURSO } \\
\text { TÉCNICO DE } \\
\text { ENFERMAGEM } \\
\text { DO IFNMG: } \\
\text { (RE)SIGNIFICAN } \\
\text { DO A } \\
\text { PERCEPÇÃO } \\
\text { DOS ALUNOS } \\
\text { EM RELAÇÃO À } \\
\text { COMUNICAÇÃO } \\
\text { COM OS } \\
\text { SURDOS NA } \\
\text { ATENÇÃO À } \\
\text { SAÚDE / IFNMG / } \\
\text { BarrosO (2020) }\end{array}$ & $\begin{array}{l}\text { descritiva, } \\
\text { bibliográfica e } \\
\text { pesquisa-ação com } \\
\text { abordagem } \\
\text { qualitativa. Como } \\
\text { instrumentos de } \\
\text { coleta de dados } \\
\text { foram utilizados a } \\
\text { entrevista, o } \\
\text { questionário e a } \\
\text { observação direta. } \\
\\
\text { Principais autores: } \\
\text { FRIGOTTO, G.; } \\
\text { MANACORDA, M. } \\
\text { A; } \\
\text { MARX, K.; } \\
\text { FREIRE, P.; } \\
\text { AUSUBEL, D. P.; } \\
\text { NÓBREGA et al.;; } \\
\text { MOREIRA, M.A. }\end{array}$ & $\begin{array}{l}\text { auditiva e surdez. O aluno se } \\
\text { confunde ao estabelecer a } \\
\text { experiência com idosos que } \\
\text { apresentam diminuição } \\
\text { auditiva, com a experiência com } \\
\text { os surdos. Mesmo na } \\
\text { contemporaneidade, confusões } \\
\text { como estas se apresentam; } \\
\text { - Vê-se que } 67 \% \text { dos alunos } \\
\text { conhecem muito } \\
\text { superficialmente a Libras; no } \\
\text { entanto, desconhecem a } \\
\text { significação e valorização } \\
\text { identitária, social e cultural que } \\
\text { ela tem para o surdo. } \\
\text { - Percebeu-se na análise do } \\
\text { Projeto Pedagógico do Curso e } \\
\text { nas entrevistas com os alunos } \\
\text { pesquisados que o atendimento } \\
\text { ao paciente surdo não é } \\
\text { contemplado no Curso Técnico } \\
\text { em Enfermagem do IFNMG } \\
\text { - Ao longo da pesquisa } \\
\text { constatou-se para alguns } \\
\text { alunos que o curso serviu para } \\
\text { estabelecer a significação da } \\
\text { língua, como essencial para a } \\
\text { comunicação no atendimento à } \\
\text { saúde do surdo. E } \quad \text { a }\end{array}$ & $\begin{array}{l}\text { ÊNFASE NA ÁREA } \\
\text { DA SAÚDE } \\
\text { (Manual / Guia / Texto } \\
\text { de Apoio / Curso } \\
\text { Minicurso) Registro: } \\
\text { 978-65-00-09148-9 } \\
\text { O produto tem por } \\
\text { objetivo contribuir para } \\
\text { a formação dos } \\
\text { estudantes do Curso } \\
\text { Técnico de } \\
\text { Enfermagem do } \\
\text { IFNMG, através da } \\
\text { oferta de um curso de } \\
\text { curta duração em } \\
\text { Libras a fim de } \\
\text { atender a formação } \\
\text { integral e humanizada } \\
\text { do técnico em } \\
\text { enfermagem do de } \\
\text { A finalidade deste } \\
\text { produto é apresentar } \\
\text { uma proposta de } \\
\text { curso por meio do } \\
\text { ensino híbrido com } \\
\text { uma carga horária de } \\
36 \text { horas - oito horas } \\
\text { presenciais e } 28 \text { horas } \\
\text { à distância, no período } \\
\text { de dois meses e meio } \\
\text { e servir de guia e } \\
\text { material didático para } \\
\text { que cursos da área da } \\
\text { saúde possam aplicar } \\
\text { esse conteúdo para o } \\
\text { ensino dos conceitos } \\
\text { básicos de Libras aos } \\
\text { alunos de suas } \\
\text { instituições. }\end{array}$ \\
\hline $\begin{array}{l}\text { EDUCAÇÃO } \\
\text { FÍSICA } \\
\text { ESCOLAR, } \\
\text { SAÚDE } \\
\text { QUALIDADE } \\
\text { VIDA } \\
\text { CONTEXTO NO } \\
\text { FORMAÇÃO } \\
\text { HUMANA } \\
\text { INTEGRAL / IFPB } \\
\text { / Almeida (2020) }\end{array}$ & $\begin{array}{l}\text { Trata-se de um } \\
\text { estudo pré- } \\
\text { experimental, de } \\
\text { abordagem } \\
\text { quantitativa, do tipo } \\
\text { descritivo. } \\
\text { O instrumento de } \\
\text { coleta de dados } \\
\text { utilizado no estudo } \\
\text { foi o Questionário. } \\
\\
\text { Principais autores: } \\
\text { MOURA, D. H.; } \\
\text { SILVA, M. R.; } \\
\text { FILHO, D. L. L.; } \\
\text { MELO, M. T.; }\end{array}$ & $\begin{array}{l}\text { - Verificou-se, então, que houve } \\
\text { mudanças na percepção de } \\
\text { saúde e nos benefícios } \\
\text { percebidos da prática de } \\
\text { atividade física dos alunos após } \\
\text { a ação. Tais resultados nos } \\
\text { levaram a concluir que ações } \\
\text { pedagógicas para além do } \\
\text { esporte devem ser estimuladas } \\
\text { para transformar a vida dos } \\
\text { alunos em sujeitos conscientes } \\
\text { da influência da atividade física } \\
\text { para sua saúde e qualidade de } \\
\text { vida, fortalecendo, assim, a } \\
\text { importância da Educação Física } \\
\text { como componente curricular } \\
\text { indispensável para formação. }\end{array}$ & $\begin{array}{l}\text { (RE)PENSANDO } \\
\text { PRATICAS } \\
\text { PEDAGÓGICAS } \\
\text { SOBRE SAÚDE E } \\
\text { QUALIDADE DE VIDA } \\
\text { NAS AULAS DE } \\
\text { EDUCAÇÃO FÍSICA. } \\
\text { (Outro) } \\
\text { Cartilha digital sobre } \\
\text { saúde e qualidade de } \\
\text { vida para professores } \\
\text { de Educação Física a } \\
\text { partir de uma ação } \\
\text { pedagógica realizada } \\
\text { com alunos do curso } \\
\text { técnico de recursos } \\
\text { pesqueiros do campus }\end{array}$ \\
\hline
\end{tabular}




\begin{tabular}{|c|c|c|c|}
\hline & $\begin{array}{l}\text { ARAÚJO, R. M. DE } \\
\text { L; } \\
\text { FRIGOTTO, G.; } \\
\text { RAMOS, J. J.; } \\
\text { GONÇALVES, M. A. } \\
\text { S. }\end{array}$ & $\begin{array}{l}\text { - Além disso, parece-nos } \\
\text { promissora a proposta da } \\
\text { cartilha digital apresentada } \\
\text { como produto educacional, haja } \\
\text { vista a significativa capacidade } \\
\text { da mesma, servir de inspiração } \\
\text { para uma prática pedagógica } \\
\text { preocupada com a formação } \\
\text { humana integral. }\end{array}$ & $\begin{array}{l}\text { Cabedelo do Instituto } \\
\text { Federal de Educação, } \\
\text { Ciência e Tecnologia } \\
\text { da Paraíba (IFPB) }\end{array}$ \\
\hline $\begin{array}{l}\text { JOGO } \\
\text { ACIDENTE } \\
\text { ZERO: } \\
\text { ELEMENTOS DE } \\
\text { GAMIFICAÇÃO } \\
\text { PARA O ENSINO } \\
\text { E } \\
\text { APRENDIZAGEM } \\
\text { DE SAÚDE E } \\
\text { SEGURANÇA DO } \\
\text { TRABALHO EM } \\
\text { CURSO } \\
\text { TÉCNICO } \\
\text { INTEGRADO / } \\
\text { IFSUL / Einhardt } \\
\text { (2020) }\end{array}$ & $\begin{array}{l}\text { Pesquisa de } \\
\text { natureza qualitativa, } \\
\text { com técnicas de } \\
\text { coleta de dados } \\
\text { baseadas } \\
\text { especialmente em } \\
\text { realização de } \\
\text { entrevistas, } \\
\text { aplicação de } \\
\text { questionários e } \\
\text { observação. } \\
\text { Principais autores: } \\
\text { AUSUBEL, D. P. } \\
\text { FRIGOTTO, G. } \\
\text { LÜDKE, M }\end{array}$ & $\begin{array}{l}\text { O jogo foi aplicado em turma do } \\
\text { Curso Técnico Integrado em } \\
\text { Edificações do Instituto Federal } \\
\text { de Educação, Ciência e } \\
\text { Tecnologia Sul-rio-grandense } \\
\text { (IFSul) e os resultados da } \\
\text { avaliação da atividade } \\
\text { permitem inferir que os } \\
\text { elementos de gamificação } \\
\text { escolhidos contribuíram para o } \\
\text { engajamento comportamental, } \\
\text { afetivo, cognitivo e agente dos } \\
\text { alunos. }\end{array}$ & $\begin{array}{l}\text { JOGO ACIDENTE } \\
\text { ZERO } \\
\text { (Jogo / Kits } \\
\text { Interativos) } \\
\text { O jogo simula um } \\
\text { canteiro de obras e } \\
\text { solicita que os alunos } \\
\text { resolvam problemas } \\
\text { em Saúde e } \\
\text { Segurança do do d } \\
\text { Trabalho. }\end{array}$ \\
\hline $\begin{array}{l}\text { DO HUMOR AO } \\
\text { APRENDIZADO: } \\
\text { A UTILIZAÇÃO } \\
\text { DE MEMES } \\
\text { COMO } \\
\text { FERRAMENTA } \\
\text { PEDAGÓGICA } \\
\text { PARA O ENSINO } \\
\text { DA EDUCAÇÃO } \\
\text { FÍSICA NO } \\
\text { CONTEXTO DO } \\
\text { ENSINO MÉDIO } \\
\text { INTEGRADO / } \\
\text { IFS / Lima (2020) } \\
\text { *Não está } \\
\text { vinculado ao } \\
\text { objetivo do } \\
\text { trabalho }\end{array}$ & $\begin{array}{l}\text { Pesquisa de cunho } \\
\text { qualitativo utilizando } \\
\text { como instrumentos } \\
\text { dois questionários e } \\
\text { uma intervenção. } \\
\text { Quanto aos } \\
\text { procedimentos é } \\
\text { documental e de } \\
\text { campo. } \\
\text { Principais autores: } \\
\text { BOSCATTO; J. D.; } \\
\text { DARIDO, S. C.; } \\
\text { METZNER, A. C. et. } \\
\text { al.; } \\
\text { SAVIANI, D. } \\
\text { CIAVATTA, M. } \\
\text { PEREIRA, I. B.; } \\
\text { DAWKINS, R.; } \\
\text { CHAGAS; V.; }\end{array}$ & $\begin{array}{l}\text { A partir das atividades } \\
\text { realizadas pode-se observar } \\
\text { que houve um maior } \\
\text { envolvimento dos alunos com } \\
\text { os assuntos previstos nas } \\
\text { ementas para o componente } \\
\text { curricular. } \\
\text { A avaliação no geral foi positiva } \\
\text { no tocante à aplicação da } \\
\text { cartilha intitulada "Exercício } \\
\text { físico e saúde: a ciência por } \\
\text { trás dos memes" sendo } \\
\text { acrescentadas posteriormente } \\
\text { as sugestões de melhorias } \\
\text { mencionadas no questionário } \\
\text { avaliativo. }\end{array}$ & $\begin{array}{l}\text { EXERCÍCIO FÍSICO E } \\
\text { SAÚDE: A CIÉNCIA } \\
\text { POR TRÁS DOS } \\
\text { MEMES } \\
\text { (Livro) } \\
\text { A Cartilha utiliza } \\
\text { memes para o ensino } \\
\text { da Educação Física } \\
\text { no Ensino Médio } \\
\text { Integrado do campus } \\
\text { São Cristóvão no } \\
\text { curso Técnico de } \\
\text { Nível Médio em } \\
\text { Manutenção e Suporte } \\
\text { em Informática. }\end{array}$ \\
\hline $\begin{array}{l}\text { SAÚDE MENTAL } \\
\text { E O CONTEXTO } \\
\text { ESCOLAR: } \\
\text { PERCEPÇÕES } \\
\text { DE UM ESTUDO } \\
\text { DE CASO NA } \\
\text { EDUCAÇÃO } \\
\text { PROFISSIONAL / } \\
\text { IFFarroup / } \\
\text { Pacheco (2019) }\end{array}$ & $\begin{array}{l}\text { Pesquisa com } \\
\text { abordagem } \\
\text { qualitativa. Para a } \\
\text { análise dos dados, } \\
\text { a metodologia } \\
\text { utilizada foi a } \\
\text { Análise de } \\
\text { Conteúdo. } \\
\text { Principais autores: }\end{array}$ & $\begin{array}{l}\text { Foram identificados possíveis } \\
\text { fatores causadores de prejuízos } \\
\text { ao bem-estar físico e/ou } \\
\text { emocional dos estudantes: } \\
\text { dificuldades de adaptação à } \\
\text { instituição, dificuldades de } \\
\text { relacionamento, bullying e } \\
\text { pressão por bom desempenho } \\
\text { escolar. } \\
\text { De adaptação à Instituição, } \\
\text { neste estudo, motivada pela }\end{array}$ &  \\
\hline
\end{tabular}




\begin{tabular}{|c|c|c|c|}
\hline & $\begin{array}{l}\text { FRIGOTTO, G.; } \\
\text { FERRO; A. S.; } \\
\text { ANTUNES, A. A.; } \\
\text { BOCK, A. M. B.; } \\
\text { GURPILHARES, M. } \\
\text { S. S. et al.; } \\
\text { HOFFMANN, J. M. } \\
\text { L. }\end{array}$ & $\begin{array}{l}\text { distância da família e excessiva } \\
\text { carga horária e de trabalhos; } \\
\text { No entanto, não é possível } \\
\text { afirmar que os possíveis fatores } \\
\text { são exclusivamente escolares, } \\
\text { mas interdependentes e } \\
\text { interligados a outras naturezas, } \\
\text { pessoal, familiar, } \\
\text { socioeconômicos, entre outros; } \\
\text { Necessita ampliação das } \\
\text { pesquisas em vários aspectos } \\
\text { relacionados ao tema, para } \\
\text { que, a partir de novos } \\
\text { conhecimentos seja possível } \\
\text { desenvolver formas de } \\
\text { enfrentamento das } \\
\text { problemáticas relacionadas à } \\
\text { saúde mental dos estudantes } \\
\text { de forma mais efetiva. }\end{array}$ & $\begin{array}{l}\text { problematizadoras aos } \\
\text { servidores objetivando } \\
\text { contribuir no sentido } \\
\text { de estimular reflexões } \\
\text { sobre o tema e sobre } \\
\text { a atuação dos } \\
\text { servidores e da } \\
\text { Instituição frente a ele. } \\
\text { Trata-se de um site } \\
\text { construído utilizando- } \\
\text { se uma plataforma } \\
\text { online e gratuita de } \\
\text { criação e edição de } \\
\text { sites, Wix.com }\end{array}$ \\
\hline $\begin{array}{l}\text { AVALIAÇÃO DO } \\
\text { USO DOS } \\
\text { LABORATÓRIOS } \\
\text { DE } \\
\text { HABILIDADES } \\
\text { EM SAÚDE } \\
\text { COMO } \\
\text { RECURSO } \\
\text { PEDAGÓGICO } \\
\text { NO PROCESSO } \\
\text { DE FORMAÇÃO } \\
\text { PROFISSIONAL } \\
\text { DO CURSO DE } \\
\text { GRADUAÇÃO } \\
\text { EM } \\
\text { ENFERMAGEM / } \\
\text { IFF / Terra (2019) }\end{array}$ & $\begin{array}{l}\text { Trata-se de } \\
\text { pesquisa } \\
\text { bibliográfica, } \\
\text { documental e } \\
\text { pesquisa de campo, } \\
\text { com abordagem } \\
\text { quantitativa. O } \\
\text { instrumento de } \\
\text { pesquisa utilizado } \\
\text { foi o questionário } \\
\text { produzido de acordo } \\
\text { com o checklist } \\
\text { temático e a } \\
\text { entrevista. } \\
\text { Principais autores: } \\
\text { BOTOMÉ, S. P; } \\
\text { CASTANHO, M. E; } \\
\text { FREIRE, P.; } \\
\text { FRIEDLANDER, M. } \\
\text { R; } \\
\text { GOMES, C. O.; } \\
\text { SAVIANI, D. }\end{array}$ & $\begin{array}{l}\text { Foram constatados a realização } \\
\text { de atividades de pesquisa, } \\
\text { ensino e extensão pelos cursos } \\
\text { de Enfermagem e Medicina; } \\
\text { Os alunos foram unânimes em } \\
\text { afirmar que participar de } \\
\text { atividades nos laboratórios } \\
\text { influencia muito para a } \\
\text { formação profissional; } \\
\text { E como proposição para } \\
\text { trabalhos futuros pesquisas que } \\
\text { abordam o perfil das atividades } \\
\text { desenvolvidas em laboratórios } \\
\text { de habilidades, sendo das } \\
\text { ciências da saúde ou não, para } \\
\text { adequações nos espaços de } \\
\text { acordo com a demanda } \\
\text { Dentro dos cenários } \\
\text { investigados, se possível, } \\
\text { avaliar o perfil após a } \\
\text { implementação do produto } \\
\text { educacional ao público alvo }\end{array}$ & $\begin{array}{l}\text { GUIA PRÁTICO } \\
\text { PARA UTILIZAÇÃO } \\
\text { DOS } \\
\text { LABORATÓRIOS } \\
\text { INTEGRADOS DE } \\
\text { CUIDADO } \\
\text { SAÚDE. } \\
\text { (Manual / Guia / Texto } \\
\text { de Apoio) } \\
\text { O produto educacional } \\
\text { (Guia prático) foi } \\
\text { pensado para garantir } \\
\text { uma maior } \\
\text { aproximação com as } \\
\text { regras todas as } \\
\text { possibilidades de } \\
\text { extrair ao máximo os } \\
\text { recursos disponíveis } \\
\text { nos laboratórios. } \\
\text { Facilitar a } \\
\text { agendamentos } \\
\text { continuar } \\
\text { desempenhando } \\
\text { papel importante para } \\
\text { formação autônoma, } \\
\text { crítica e de qualidade } \\
\text { exigida pelos } \\
\text { profissionais da } \\
\text { saúde. a da }\end{array}$ \\
\hline $\begin{array}{l}\text { DISCURSOS E } \\
\text { ESTRATÉGIAS } \\
\text { DE PREVENÇÃO } \\
\text { DO SUICÍDIO DE } \\
\text { JOVENS } \\
\text { ESTUDANTES } \\
\text { NO } \\
\text { IFSUL/CAMPUS }\end{array}$ & $\begin{array}{l}\text { Trata-se de uma } \\
\text { investigação que } \\
\text { teve uma } \\
\text { abordagem } \\
\text { qualitativa. A } \\
\text { investigação utilizou } \\
\text { como ferramentas } \\
\text { analíticas as noções }\end{array}$ & $\begin{array}{l}\text { É necessário incluir as } \\
\text { questões da saúde mental nos } \\
\text { currículos e nos projetos de } \\
\text { ensino, levando em conta } \\
\text { aqueles profissionais e alunos } \\
\text { que se sintam instados a falar } \\
\text { ou não, mas que não concorra } \\
\text { com as disciplinas do currículo }\end{array}$ & $\begin{array}{lr}\text { PROPOSTA } & \text { DE } \\
\text { ROTEIRO } & \text { DE } \\
\text { INTERVENÇÃO } & \\
\text { PARA O } & \text { NUPPS } \\
\text { (NÚCLEO r } & \text { DE } \\
\text { PROMOÇÃO } & \text { E } \\
\text { PREVENÇÃO } & \text { EM } \\
\text { SAÚDE) (Proposta de }\end{array}$ \\
\hline
\end{tabular}




\begin{tabular}{|c|c|c|c|}
\hline $\begin{array}{l}\text { PELOTAS: } \\
\text { RESSONÂNCIAS } \\
\text { E } \\
\text { POSSIBILIDADE } \\
\text { S DE } \\
\text { DESCONSTRUÇ } \\
\text { ÕES / IFFarroup / } \\
\text { Farias (2019) }\end{array}$ & $\begin{array}{l}\text { de discurso, poder e } \\
\text { verdade. A analítica } \\
\text { ocorreu em } 3 \\
\text { etapas: descrição e } \\
\text { análise dos } \\
\text { discursos } \\
\text { enunciados nas } \\
\text { notícias do Portal } \\
\text { Institucional do } \\
\text { IFSul/Campus } \\
\text { Pelotas. Uso da } \\
\text { roda de conversa } \\
\text { como metodologia } \\
\text { para falar sobre a } \\
\text { questão do suicídio. } \\
\\
\text { Principais autores: } \\
\text { BOTEGA, N. J.; } \\
\text { ARIÉS, P.; } \\
\text { FOUCAULT, M.; } \\
\text { FISCHER, R. M. B.; } \\
\text { MARX, K.; } \\
\text { FAÇANHA, J. D. N. } \\
\text { ET AL. }\end{array}$ & $\begin{array}{l}\text { integrado, que possam atuar } \\
\text { juntos; } \\
\text { Que agregue aos mesmos, } \\
\text { para que tenha a mesma } \\
\text { importância e seja levado em } \\
\text { consideração pelos alunos, } \\
\text { como uma forma de formação } \\
\text { plena e integral, não apenas } \\
\text { como uma formação específica } \\
\text { para o mercado de trabalho. } \\
\text { A aprendizagem passa pela } \\
\text { manutenção da saúde mental e } \\
\text { da prevenção do suicídio e } \\
\text { consequentemente da } \\
\text { manutenção do sucesso } \\
\text { escolar e de uma vida com } \\
\text { qualidade. }\end{array}$ & 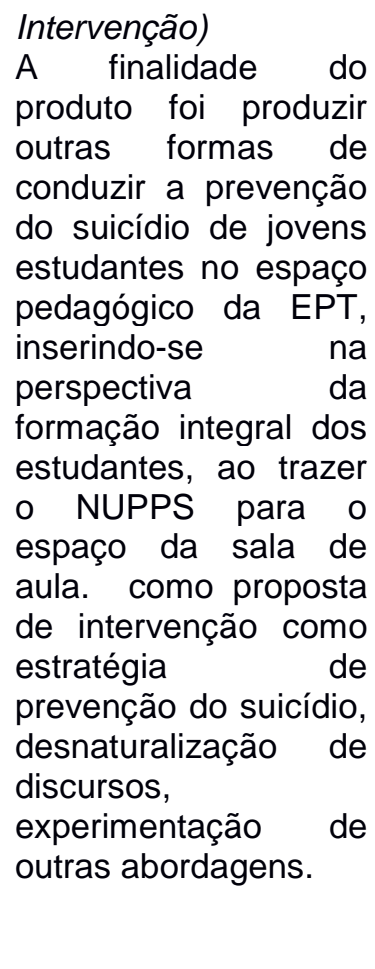 \\
\hline $\begin{array}{l}\text { EDUCAÇÃO EM } \\
\text { SAÚDE PARA } \\
\text { TRABALHADOR } \\
\text { ES E } \\
\text { TRABALHADOR } \\
\text { AS DO CAMPO: } \\
\text { UMA } \\
\text { EXPERIÊNCIA } \\
\text { EXTENSIONISTA } \\
\text { / IFRN / } \\
\text { Cavalcanti Filho } \\
\text { (2019). }\end{array}$ & $\begin{array}{l}\text { Pesquisa tipo: } \\
\text { pesquisa-Ação sob } \\
\text { uma abordagem } \\
\text { qualitativa, } \\
\text { utilizando-se de } \\
\text { dados } \\
\text { socioeconômicos e } \\
\text { de saúde dos } \\
\text { indivíduos com uso } \\
\text { da técnica da } \\
\text { observação } \\
\text { assistemática } \\
\text { participante durante } \\
\text { toda a investigação. } \\
\\
\text { Principais autores: } \\
\text { FREIRE, P.; } \\
\text { GADOTTI, M; } \\
\text { BORDENAVE, J. D; } \\
\text { BARDIN, L. }\end{array}$ & $\begin{array}{l}\text { A falta de uma política de saúde } \\
\text { que priorize ações educativas e } \\
\text { preventivas em saúde bucal, o } \\
\text { atendimento odontológico é } \\
\text { complemento necessário da } \\
\text { educação em saúde que } \\
\text { executamos, servindo de meio } \\
\text { para a detecção do câncer } \\
\text { bucal na comunidade do } \\
\text { Assentamento. Criamos, assim, } \\
\text { um momento para os } \\
\text { trabalhadores objetivarem o } \\
\text { câncer da cavidade oral e do } \\
\text { lábio e pronunciá-lo, ampliando } \\
\text { seus conhecimentos sobre o } \\
\text { tema, no dinâmico processo, } \\
\text { nem sempre regular e contínuo } \\
\text { devido às forças opressivas da } \\
\text { economia de mercado, de } \\
\text { humanizar-se. }\end{array}$ & $\begin{array}{l}\text { DIÁLOGOS SOBRE } \\
\text { CÂNCER BUCAL } \\
\text { COM } \\
\text { TRABALHADORES E } \\
\text { TRABALHADORAS } \\
\text { DOS } \\
\text { ASSENTAMENTOS } \\
\text { RURAIS, MUNICÍPIO } \\
\text { DE IGUATU - CE } \\
\text { (Manual / Guia / Texto } \\
\text { de Apoio) Registro: } \\
\text { http://educapes.capes. } \\
\text { gov.br/handle/capes/5 } \\
\text { 68909 }\end{array}$ \\
\hline $\begin{array}{l}\text { "EU LEMBRO } \\
\text { COMO SE } \\
\text { FOSSE HOJE": } \\
\text { MEMÓRIAS DO } \\
\text { CURSO } \\
\text { TÉCNICO EM } \\
\text { AGENTE } \\
\text { COMUNITÁRIO } \\
\text { DE SAÚDE - } \\
\text { PROEJA, DO IF } \\
\text { SUDESTE MG - } \\
\text { CAMPUS RIO } \\
\text { POMBA / IF }\end{array}$ & $\begin{array}{l}\text { DISSERTAÇÃO } \\
\text { NÃO } \\
\text { ENCONTRADA NA } \\
\text { PÁGINA DA CAPES } \\
\text { NEM NO SITE DO } \\
\text { IF SUDESTE DE } \\
\text { MINAS }\end{array}$ & & $\begin{array}{l}\text { RESGATAR A } \\
\text { MEMÓRIA PARA } \\
\text { CONSTRUIR UMA } \\
\text { NOVA HISTÓRIA: } \\
\text { CURSO TÉCNICO } \\
\text { EM } \\
\text { COMUNITÁRIO DENTE } \\
\text { SAÚDE - PROEJA } \\
\text { (Mídia Educacional } \\
\text { (vídeos, animações e } \\
\text { áudios)) }\end{array}$ \\
\hline
\end{tabular}




\begin{tabular}{|l|l|l|l|}
\hline $\begin{array}{l}\text { SUDESTE MG / } \\
\text { Costa (2021) } \\
\text { *Não está } \\
\text { vinculado ao } \\
\text { objetivo do } \\
\text { trabalho }\end{array}$ & & & \\
\hline $\begin{array}{l}\text { TOTAL DE } \\
\text { ESTUDOS }\end{array}$ & 13 & & \\
\hline
\end{tabular}

Fonte: IFTM - Observatório do ProfEPT.(2021)

\section{CONCLUSÕES}

A presente pesquisa buscou analisar os dados sobre o absenteísmo-doença dos servidores do IFMT no ano de 2019, bem como, as pesquisas desenvolvidas no âmbito do Programa de Mestrado Profissional em Educação Profissional e Tecnológica nos anos de 2019 e 2021, que tratou da temática da saúde dos servidores. É importante registrar que ocorreram limitações, visto que apenas os dados do SIASS de 2019 estavam disponíveis, não sendo possível verificar sobre as licenças de saúde de 2020 e 2021.

Contudo, pode-se considerar que teve seu objetivo alcançado, visto que constatou-se por meio do levantamento realizado na plataforma Observatório do ProfEPT, que o número de pesquisas voltadas para esse tema é demasiadamente baixa. No entanto, o assunto abordado sobre a saúde dos servidores que mais correlacionou com essa pesquisa é de muita relevância atualmente - a saúde mental no trabalho.

Ainda assim, evidencia-se a necessidade de aprofundamento no assunto, uma vez que os dados encontrados nos grupos de doenças que mais afastam os servidores: F00-F99 - transtornos mentais e comportamentais; o Z00-Z99 Fatores que influenciam o estado de saúde e o contato com os serviços de saúde; e - M00-M99 - Doenças do sistema osteomuscular e do tecido conjuntivo, não esclarecem se as motivações dos afastamentos são ocasionadas apenas pelo trabalho.

Por fim, constata-se também a importância em conhecer os indicadores de absenteísmo-doença dos servidores públicos, uma vez que possibilitam ao gestor do órgão, a proposição e o direcionamento de intervenções nos espaços laborais dos grupos ocupacionais com maior potencial para adoecimento.

\section{REFERÊNCIAS}

ALMEIDA, L. G. M. DE. Educação física escolar, saúde e qualidade de vida no contexto da formação humana integral. Dissertação (Mestrado em Educação Profissional e Tecnológica) - Instituto Federal da Paraíba - Campus João Pessoa IFPB/ Programa de Pós-Graduação em Educação Profissional ProfEPT. 2020. Disponível em: https://bit.ly/3qKg9NU. Acesso em: 14 nov. 2021.

ANTUNES, J. R. Saúde Mental do Servidor Público Federal na Educação Profissional e Tecnológica: um enfoque teórico-prático a partir do câmpus Pinhais. Dissertação (Mestrado em Educação Profissional e Tecnológica) - Instituto Federal do Paraná - IFPR/ Programa de Pós-Graduação em Educação Profissional ProfEPT. 2019. Disponível em: https://bit.ly/3qCBPLW. Acesso em: 14 nov. 2021. 
BARROSO, H. S. M. B. A Língua Brasileira de Sinais (Libras) no curso Técnico de Enfermagem do IFNMG: (re)significando a percepção dos alunos em relação à comunicação com os surdos na atenção à saúde. Dissertação (Mestrado em Educação Profissional e Tecnológica) - Instituto Federal do Norte de Minas Gerais IFNMG/ Programa de Pós-Graduação em Educação Profissional ProfEPT. 2020. Disponível em: https://bit.ly/3nd8yFw. Acesso em: 14 no. 2021.

BRASIL. Decreto $n^{\circ}$ 6.833, de 29 de abril de 2009. Institui o Subsistema Integrado de Atenção à Saúde do Servidor Público Federal - SIASS e o Comitê Gestor de Atenção à Saúde do Servidor. Diário Oficial da União 2009. Disponível em: https://bityli.com/qbve4k. Acesso em: 01 nov. 2021.

BRASIL. Ministério da Economia. Secretaria de Previdência. Acompanhamento Mensal do Benefício Auxílio-Doença Previdenciário Concedido Segundo os Códigos da CID-10 - Janeiro a Dezembro de 2019. Disponível em: https://bityli.com/4NqG5o. Acesso em: 05 nov. 2021.

BRASIL. Ministério do Planejamento, Orçamento e Gestão. Secretaria de Recursos Humanos. Manual de Perícia Oficial em Saúde do Servidor Público Federal. Brasília, 2017.

CAVALCANTI FILHO, A. S. Educação em saúde para trabalhadores e trabalhadoras do campo: uma experiência extensionista em Mossoró/ RN. Dissertação (Mestrado em Educação Profissional e Tecnológica) - Instituto Federal de Educação, Ciência e Tecnologia do Rio Grande do Norte/ Programa de PósGraduação em Educação Profissional ProfEPT, 2019. Disponível em: https://bit.ly/3FdHex8. Acesso em: 14 nov. 2021.

CODO, W.; VASQUES-MENEZES, I. Burnout: sofrimento psíquico dos trabalhadores em educação. Caderno de Saúde do Trabalhador. Instituto Nacional de Saúde no Trabalho, São Paulo, 2000.

COSTA, N. S. "Eu lembro como se fosse hoje: memórias do curso técnico em agente comunitário de saúde - Proeja, do IF Sudeste MG - Campus Rio Pomba. Dissertação (Mestrado em Educação Profissional e Tecnológica) - Instituto Federal do Sudeste de Minas Gerais - IF Sudeste MG/ Programa de Pós-Graduação em Educação Profissional ProfEPT. 2021. Disponível em: https://bit.ly/3Ck9Se6. Acesso em: 14 nov. 2021.

CUNHA, J. B.; BLANK, V. L. G.; BOING, A. F. Tendência temporal de afastamento do trabalho em servidores públicos (1995-2005). Revista Brasileira de Epidemiologia, 2009. Disponível em: https://bityli.com/Mkyej0. Acesso em: 01 nov. 2021.

DALCIN, L.; CARLOTTO, M. S. Síndrome de burnout em professores no Brasil: considerações para uma agenda de pesquisa. Psicologia em Revista, Belo Horizonte, v. 23, n. 2, p. 745-771, ago. 2017. Disponível em: https://bityli.com/PUSihq. Acesso em: 01 nov. 2021.

EINHARDT, L. W. Jogo Acidente Zero: elementos de gamificação para o ensino e aprendizagem de saúde e segurança do trabalho em curso técnico integrado. 
Dissertação (Mestrado em Educação Profissional e Tecnológica) - Instituto Federal do Sul-rio-grandense - IFSul/ Programa de Pós-Graduação em Educação Profissional ProfEPT. 2020. Disponível em: https://bit.ly/3Dk8bPk. Acesso em: 14 nov. 2021.

FARIAS, M. F. R. Discursos e estratégias de prevenção do suicídio de jovens estudantes no IFSUL/Campus Pelotas: ressonâncias e possibilidades de desconstruções. Dissertação (Mestrado em Educação Profissional e Tecnológica) Instituto Federal de Educação, Ciência e Tecnologia de Santa Maria/RS / Programa de Pós-Graduação em Educação Profissional ProfEPT, 2019. Disponível em: https://bit.ly/3nbBU7k. Acesso em: 14 nov. 2021.

FIGUEIREDO, B. DE. O. Absenteísmo-doença de servidores da educação: perfil dos afastamentos em uma instituição federal. Dissertação. (Mestrado em Ciências da Saúde). Universidade Federal de Viçosa. Viçosa, MG, 2019.

GODOY, A. S. Introdução à pesquisa qualitativa e suas possibilidades. Revista de Administração de Empresas. São Paulo, v. 35, n. 2, Mar./Abr., p. 57-635. 1995. Disponível em: https://bit.ly/2ZLBJ9N. Acesso em: 01 dez. 2021.

GOMES, A. R. Realização da SIPAT em uma unidade da Rede Federal de Educação, Ciência e Tecnologia como forma de promover a segurança do trabalho no ensino técnico e tecnológico. Dissertação (Mestrado em Educação Profissional e Tecnológica) - Instituto Federal de Mato Grosso - IFMT/ Programa de Pós-Graduação em Educação Profissional ProfEPT. 2020. Disponível em: https://bit.ly/30opJLY. Acesso em: 14 nov. 2021.

IFES. Instituto Federal do Espírito Santo. Área de Concentração: Mestrado Profissional em Educação Profissional e Tecnológica em Rede Nacional. 2021.

JORGE, J. D. P. Proposta para promoção da saúde mental discente no contexto da Educação Profissional e Tecnológica. Dissertação (Mestrado em Educação Profissional e Tecnológica) - Instituto Federal de São Paulo - IFSP/ Programa de Pós-Graduação em Educação Profissional ProfEPT. 2019. Disponível em: https://bit.ly/3cd54g8. Acesso em: 14 nov. 2021.

LEMOS, D. S.; ESCALDA, P. M. F.; PAZ, L. P. S.; LEÃO, A. L. M. Absenteísmodoença entre servidores públicos do setor saúde do Distrito Federal. Revista Brasileira de Medicina do Trabalho. 2018. Disponível em: https://bityli.com/NviEUI. Acesso em: 30 out. 2021. DOI: 10.5327/Z1679443520180246

LIMA, U. D. Do humor ao aprendizado: a utilização de memes como ferramenta pedagógica para o ensino da educação física no contexto do ensino médio integrado. Dissertação (Mestrado em Educação Profissional e Tecnológica) Instituto Federal de Sergipe- IFSE / Programa de Pós-Graduação em Educação Profissional ProfEPT. 2020. Disponível em: https://bit.ly/3kBhrHv. Acesso em: 14 nov. 2021.

LUZ JÚNIOR, A. F. Saúde do trabalhador: a contribuição dos conhecimentos em saúde sob uma perspectiva ampliada para a formação profissional e tecnológica integrada ao ensino médio. Dissertação (Mestrado em Educação 
Profissional e Tecnológica) - Instituto Federal do Espírito Santo - IFES/ Programa de Pós-Graduação em Educação Profissional ProfEPT, Vitória/ES. 2020. Disponível em: https://bit.ly/3wKYK8R. Acesso em: 14 nov. 2021.

MAIA, D. A. Segurança e saúde do trabalho em laboratórios de ensino: proposta de um manual para prevenção de riscos e de acidentes. Dissertação (Mestrado em Educação Profissional e Tecnológica) - Instituto Federal do Rio Grande do Norte - IFRN/ Programa de Pós-Graduação em Educação Profissional ProfEPT. 2019. Disponível em: https://bit.ly/3FfgZX3. Acesso em: 14 nov. 2021.

MARTINS, M. I. C.; OLIVEIRA, S. S.; ANDRADE, E. T.; STRAUZZ, M. C.; CASTRO, L. C. F.; AZAMBUJA, A. A política de atenção à saúde do servidor público federal no Brasil: atores, trajetórias e desafios. Ciência \& Saúde, Coletiva 2017. Disponível em: https://bityli.com/JaJeQK. Acesso em: 01 nov. 2021.

MEDICINANET. Portal Médico do Brasil, CID10. Disponível em: https://www.medicinanet.com.br/cid10.htm. Acesso em: 07 nov. 2021.

MENDES, M. L. M. A tradução do fracasso: Burnout em Professores do Recife. Tese (Doutorado no Programa de Pós-Graduação em Educação) - Universidade Federal de Pernambuco. Pernambuco, 2015.

MIDORIKAWA, S. K. Saúde vocal dos servidores docentes da educação profissional e tecnológica: condições de voz dos professores no âmbito do IFPR - campus Curitiba. Dissertação (Mestrado em Educação Profissional e Tecnológica) - Instituto Federal do Paraná - IFPR/ Programa de Pós-Graduação em Educação Profissional ProfEPT. 2021. Disponível em: https://bit.ly/3HINsNn. Acesso em: 14 nov. 2021.

MINAYO, M. C. de S. (Org.); DESLANDES, S. F. e GOMES, R. Pesquisa social: teoria, método e criatividade. Petrópolis/RJ: Vozes, 2015.

MOUSINHO, A. C. S. A. S. A percepção de quem cuida: saúde mental de estudantes sob a ótica das equipes de saúde, pedagógica e de assistência estudantil. Dissertação (Mestrado em Educação Profissional e Tecnológica) Instituto Federal da Paraíba - IFPB/ Programa de Pós-Graduação em Educação Profissional ProfEPT. 2021. Disponível em: https://bit.ly/3FvQ9dF. Acesso em: 14 nov. 2021.

MURCHO, N. A. C.; JESUS, S. N. Absenteísmo no trabalho. In: M. M. M. Siqueira (Org.) Novas Medidas do Comportamento Organizacional: ferramentas de diagnóstico e de gestão. 1a ed., p.15-24, 2014. Artmed. Disponível: https://bityli.com/zc0cs1. Acesso em: 01 nov. 2021.

PACHECO, F. A. Saúde mental e o contexto escolar: percepções de um estudo de caso na educação profissional. Dissertação (Mestrado em Educação Profissional e Tecnológica) - Instituto Federal Farroupilha - Jaguari / Programa de Pós-Graduação em Educação Profissional ProfEPT. 2019. Disponível em: https://bit.ly/3ChRF0C. Acesso em: 14 nov. 2021. 
PENNATI, I; ZAGO, S. J; QUELHAS, O. Absenteísmo: As consequências na gestão de pessoas. Disponível em: https://bityli.com/5YUdE0. Acesso em: 01 nov. 2021.

SANTI, D. B.; BARBIERI, A. R.; CHEADE, M. DE F. M. Absenteísmo-doença no serviço público brasileiro: uma revisão integrativa da literatura. Revista Brasileira de Medicina do Trabalho, 2017. Disponível em: https://bit.ly/3CinoyV. Acesso em: 01 nov. 2021. DOI: $10.5327 / Z 1679443520180084$

SANTOS, L. A. "Quando chega domingo, fico triste de ter que trabalhar na segunda": A Qualidade de Vida no Trabalho em questão no Serviço Público Federal. 2014. Universidade de Brasília.

SAVIANI, D. Trabalho e Educação: fundamentos ontológicos e históricos. Revista Brasileira de Educação, v. 12 n. 34 jan./abr. 2007.

SOUZA, F. L. R. DE. Estratégias de práticas de educação em saúde para a formação integral de discentes dos cursos técnicos integrados do Instituto Federal Farroupilha Campus Jaguari. Dissertação (Mestrado em Educação Profissional e Tecnológica) - Instituto Federal Farroupilha- IFFarroup - Jaguari, RS. Programa de Pós-Graduação em Educação Profissional ProfEPT. 2020a. Disponível em: https://bit.ly/3qEiom2. Acesso em: 14 nov. 2021.

SOUZA, J. S. F. DE. Avalie Saúde: uma proposta educacional tecnológica voltada para os docentes de Educação Física da Educação Profissional e Tecnológica. Dissertação (Mestrado em Educação Profissional e Tecnológica) Instituto Federal do Paraná - IFPR/ Programa de Pós-Graduação em Educação Profissional ProfEPT. 2020b. Disponível em: https://bit.ly/3ndqyQ8. Acesso em: 14 nov. 2021.

TERRA. M. L. Avaliação do uso dos laboratórios de habilidades em saúde como recurso pedagógico no processo de formação profissional do curso de graduação em enfermagem. Dissertação (Mestrado em Educação Profissional e Tecnológica) - Instituto Federal Fluminense - Campos dos Goytacases - IFF/ Programa de Pós-Graduação em Educação Profissional ProfEPT. 2019. Disponível em: https://bit.ly/3DiXnAG. Acesso em: 14 nov. 2021.

UFABC. Universidade Federal do ABC. Análise dos afastamentos de saúde dos servidores. Unidade SIASS - Fundação Universidade Federal do ABC - Sede. 2019. Disponível em: https://bit.ly/3ljOD6H. Acesso em: 29 nov. 2021.

VIAPIANA, V. N. GOMES, S. M. ALBUQUERQUE, G. S. C. Adoecimento psíquico na sociedade contemporânea: notas conceituais da teoria da determinação social do processo saúde doença. Revista Saúde e Debate, v. 42, n. especial 4, p.175-186, Rio De Janeiro, 2018. Disponível em: https://bit.ly/3qzEjLc. Acesso em: 15 nov. 2021. DOI: $10.1590 / 0103-11042018 S 414$ 